\title{
El elemento endémico de la flora vascular del Desierto Chihuahuense
}

\section{The endemic element of the Chihuahuan Desert vascular flora}

\author{
José A. Villarreal-Quintanillal,4 (D), Jenry A. Bartolomé-Hernández (D), Eduardo Estrada-Castillón³, \\ Homero Ramírez-Rodríguez² (1) y Silvia J. Martínez-Amador' (B)
}

1 Universidad Autónoma Agraria Antonio Narro, Departamento de Botánica, Calzada Antonio Narro 1923, Buenavista, 25315 Saltillo, Coahuila, México.

2 Universidad Autónoma Agraria Antonio Narro, Departamento de Horticultura, Calzada Antonio Narro 1923, Buenavista, 25315 Saltillo, Coahuila, México.

3 Universidad Autónoma de Nuevo León, Facultad de Ciencias Forestales, Apdo. postal 41, 67700 Linares, Nuevo León, México.

4 Autor para la correspondencia: javillarrealOO@hotmail.com

\section{Citar como}

Villarreal-Quintanilla, J. A., J. A Bartolomé-Hernández, E. EstradaCastillón, H. Ramírez-Rodríguez y S. J. Martínez-Amador. 2017. El elemento endémico de la flora vascular del Desierto Chihuahuense. Acta Botanica Mexicana 118: 65-96. DOI: http://dx.doi.org/10.21829/abm118. 2017.1201

Recibido: 9 de junio de 2015. Revisado: 10 de febrero de 2016 Aceptado: 22 de septiembre de 2016

DOI:

http://dx.doi.org/10.21829/abml18. 2017.1201

\section{Resumen:}

Antecedentes y Objetivos: El endemismo es un fenómeno común de los organismos en las regiones áridas. En el presente trabajo se revisó la distribución de las plantas endémicas del Desierto Chihuahuense (DCH), cuya superficie abarca parte de los estados de Arizona, Chihuahua, Coahuila, Durango, Nuevo León, Nuevo México, San Luis Potosí, Tamaulipas, Texas y Zacatecas.

Métodos: A través de la recopilación de información se elaboró una base de datos de especies con distribución restringida al DCH. Se consideraron los siguientes tipos de endemismo: 1) endémicos estrictos: aquellos elementos con localización conocida solo para el área de estudio, 2) cuasi-endémicos: aquellos presentes principalmente en el DCH y algunas poblaciones en localidades vecinas, 3) micro-endémicos: los que tienen una distribución restringida a una sola localidad y 4) endémicos a la región, pero de ecosistemas no áridos.

Resultados clave: Se identificaron 826 taxa (incluye especies, taxa infraespecíficos adicionales e híbridos) que representan $24.87 \%$ de la flora total, 560 elementos de distribución endémica, 165 cuasi-endémicos, 176 micro-endémicos y 116 de ecosistemas no áridos. Las familias con mayor cantidad de endemismos son Cactaceae (141 especies), Asteraceae (106), Boraginaceae (34) y Brassicaceae (31) que en conjunto representan $46.2 \%$ del total. Los géneros con mayor número de taxa son Coryphantha (24), Echinocereus (14), Mammillaria (15) y Turbinicarpus (15), así como nueve géneros exclusivos al DCH. Las formas biológicas dominantes son las hierbas perennes y arbustivas, presentándose frecuentemente en el matorral xerófilo. La distribución endémica es de forma heterogénea, con una densidad de 0.128 especies $/ \mathrm{km}^{2}$. Coahuila concentra la mayor proporción de elementos $(31.15 \%)$.

Conclusiones: Se sugiere continuar con la protección de Cuatro Ciénegas, Brewster, las Sierras La Madera y El Carmen y proponer como áreas de conservación a las Sierras de Parras, La Paila y Jimulco, y Concepción del Oro y Presidio, por presentar una alta concentración de endemismos.

Palabras clave: conservación, desiertos, fitogeografía, zonas áridas.

\section{ABSTRACT:}

Background and Aims: Endemism is a common phenomenon in arid regions. In this study we reviewed the distribution of endemic plants in the Chihuahuan Desert (DCH), which includes portions of the states of Arizona, Chihuahua, Coahuila, Durango, Nuevo Leon, Nuevo Mexico, San Luis Potosi, Tamaulipas, Texas and Zacatecas.

Methods: A database was set up summarizing the information on the restricted species from the DCH. The following types of endemism were considered: 1) endemics which are known from the study region only, 2) quasi-endemics with distribution mainly in the $\mathrm{DCH}$ and some populations in the neighboring areas, 3) micro-endemics which are restricted to one location, and 4) endemics of non-arid habitats in the area.

Key results: A total of 826 taxa (including species, additional infraspecific taxa and hybrids) were determined to be endemics or quasi-endemics, representing $24.87 \%$ of the total flora. Of this, 560 are endemics, 165 quasi-endemics, 176 micro-endemics and 116 are from non arid habitats. The families with the most endemics are Cactaceae (141 species), Asteraceae (106), Boraginaceae (34) and Brassicaceae (31), that represent $46.2 \%$ of the total. The genera with the highest taxa numbers are Coryphantha (24), Echinocereus (14), Mammillaria (15), Turbinicarpus (15). Nine genera are exclusive to the DCH. The dominant biological forms are perennial herbs and shrubs, frequently distributed in the xeric shrubland. The endemic distribution is heterogeneous, with a density index of $0.128 \mathrm{species} / \mathrm{km}^{2}$. Coahuila has the largest number of elements $(31.15 \%)$.

Conclusions: It is suggested to continue the protection of Cuatro Ciénegas, and portions of Brewster, as well as the Sierras La Madera and El Carmen. Sierras de Parras, La Paila and Jimulco, and Concepción del Oro and Presidio, are proposed as conservation areas, as they concentrate a large number of endemic species.

Keys words: arids zones, conservation, deserts, phytogeography. 


\section{INTRODUCCIÓN}

El nombre de Desierto Chihuahuense (DCH) se remonta a 1843 , cuando R. B. Hinde habló vagamente de una "Región Chihuahuense"; sin embargo, a partir de 1940, se empezó a denominar el Desierto Chihuahuense como una región ecológica (Morafka, 1977). Es considerado el desierto más grande de Norte América (Cloudsley, 1977) y el segundo con mayor diversidad a nivel mundial. Comenzó a formarse hace unos cinco millones de años en el Plioceno y ocupa un área aproximada de 505,000 km². Se origina en el altiplano de México entre la Sierra Madre Occidental y la Sierra Madre Oriental, continúa hacia el norte hasta el sur de Arizona, Nuevo México y Texas, e incluye parte de los estados mexicanos de Chihuahua, Coahuila, Durango, Nuevo León, San Luis Potosí, Tamaulipas y Zacatecas. Su extensión en México ocupa alrededor de un sexto de la superficie territorial mexicana (Henrickson y Johnston, 2007). Es un desierto zonal por encontrarse ligado a la presencia de altas presiones tropicales, así como por ubicarse en una vasta región alejada de las masas de aire marítimo. Abarca una de las regiones áridas biológicamente más ricas de la tierra; su riqueza florística y endémica engrandece la diversidad biológica de nuestro país (Balleza y Villaseñor, 2011).

Esta región se encuentra a una altitud entre los 1000 y $3050 \mathrm{~m}$, y la mayor parte de su superficie se encuentra formada por suelos calcáreos derivados de camas de piedra caliza. El régimen climático incluye inviernos fríos y secos, con frecuentes temperaturas bajo cero y nevadas ocasionales, así como veranos calurosos. El rango de la temperatura anual es de $5.5-35{ }^{\circ} \mathrm{C}$ y precipitaciones anuales oscilan entre 175 y $400 \mathrm{~mm}$ (Henrickson y Johnston, 2007). No tiene una delimitación definida, las Sierras Madres Occidental y Oriental se consideran los límites oeste y este, pero los límites precisos de la frontera en el norte y sur están sujetos a debate. Existen diversas propuestas para su definición, como la de Morafka (1977), basada en la distribución de anfibios y reptiles; las de Henrickson y Straw (1976) y Shreve (1942) que toman como base la vegetación; las de Henrickson y Johnston (2007), Hernández et al. (2004), Johnston (1974) y Muldavin (2002), quienes consideran la composición florística; CONABIO (1999) la fundamenta en las características topográficas, Schmidt (1979) en la edafología, datos climáticos y topográficos, y Medellín (1982) en el índice de aridez.

Es una de las regiones ecológicas biológicamente más ricas del mundo, aunque su biodiversidad no es lo único por reconocer, ya que su alta riqueza endémica también es sobresaliente. El alto grado de endemismo es el resultado de los efectos de aislamiento, de la fisiografía, de los cambios dinámicos en el clima durante los últimos 10,000 años y de la colonización de hábitats por elementos especialistas. Aquí se albergan numerosos taxa que se encuentran en alguna categoría de riesgo, desde especies en protección especial hasta en peligro de extinción (SEMARNAT, 2010). Se han enumerado 3382 especies de plantas, entre las que se incluyen un gran número de elementos restringidos (Henrickson y Johnston, 2007). Además, alberga el más rico ensamblaje de cactáceas en el mundo (Hernández et al., 2004).

La palabra endemismo procede del vocablo "endemia" o "enfermedad endémica", que es propia de un territorio determinado donde se mantiene permanentemente (Sainz y Moreno, 2002). De Candolle (1820) utilizó este término por primera vez en sentido botánico, para referirse a las familias que crecían en un solo país. México se caracteriza por poseer una gran cantidad de plantas endémicas; esto representa cerca de $40 \%$ de las 23,000 especies descritas para el país (CONABIO, 1998). La importancia de los elementos de distribución restringida resulta de gran interés desde el punto de vista florístico ya que indican condiciones especiales de suelo, clima, regiones de aislamiento ecológico y especialmente son útiles para la determinación de áreas de protección ambiental (Villaseñor, 1991). Los endemismos, en particular a nivel de especie, sobre todo son frecuentes en regiones templadas y subhúmedas, zonas áridas y semiáridas (Rzedowski, 1991a). El aislamiento y las condiciones bioclimáticas del DCH han resultado en un refugio ideal para estos elementos (Moore, 2014).

Los taxa endémicos constituyen una indudable atracción; sin embargo, son pocos los trabajos sobre en- 
demismo para regiones o grupos taxonómicos específicos (Espejo, 2012). El descubrimiento de nuevas especies, el cambio de categoría taxonómica y los patrones de distribución, incluyendo la información carente para algunas regiones, hacen que el estudio de los inventarios de la riqueza biológica de México y su nivel de endemismo sea una tarea aún incompleta (Villaseñor, 1991; SEMARNAT, 2005). El generar un acervo de información con aspectos biológicos, ecológicos y geográficos para un grupo biológico, o lugar, es uno de los grandes desafíos que hoy se enfrenta y además es prioritario, ya que parte del éxito en la conservación biológica depende en gran medida del conocimiento de las especies o sistemas que se desean proteger. Esta investigación presenta un análisis de la flora endémica del $\mathrm{DCH}$ con el propósito de identificar las áreas con mayor concentración de elementos endémicos y proponer lugares prioritarios para la conservación de la riqueza florística de esta región.

\section{Materiales y Métodos}

Para este trabajo se consideraron como especies endémicas aquellas cuya área de distribución es exclusiva o casi-exclusiva al DCH. En la delimitación del área se siguió el criterio florístico propuesto por Johnston (1974) y como base para la revisión de la flora el estudio de Henrickson y Johnston (2007). Para complementar el listado se realizó una revisión bibliográfica lo más completa posible (monografías, estudios taxonómicos, trabajos florísticos, etc.), relativos a la flora del Desierto Chihuahuense o floras de los estados y/o regiones que lo conforman, enfocada a los taxa de distribución restringida. Además, se realizó una revisión de ejemplares de interés en el herbario ANSM. Se capturó información taxonómica, forma biológica, tipo de vegetación y distribución por especie (Apéndice). La nomenclatura y clasificación de los taxa se cotejó con las bases de datos del International Plant Names Index (IPNI, 2016), The Plant List (The Plant List, 2013), y Tropicos (2016). Para la autoría y aceptación de nombres se siguió la base de datos de Tropicos; únicamente para las Asparagaceae endémicas se siguió a González et al. (2011).
Toda la información se resumió en una base de datos la cual incluyó información taxonómica (división, familia, género y especie), tipo de endemismo (endémico o cuasi-endémico), forma biológica, tipo de vegetación, entidades federativas, localidades y especies micro-endémicas, así como de regiones no áridas.

Para conocer la distribución general de las especies en el DCH, el área se dividió en cuatro partes, siguiendo los trazos de la parte media horizontal y vertical. Se contabilizó la presencia de los taxa en cada uno de los cuatro cuadrantes para comparar la proporcionalidad de cada uno de ellos. Se estimó el índice de densidad (Delgadillo et al., 2003) para el área del DCH y otras regiones con endemismos.

\section{Resultados y Discusión}

La riqueza de plantas endémicas del Desierto Chihuahuense consta de 67 familias, 263 géneros, 671 especies y 155 taxa infraespecíficos (73 subespecies, 79 variedades y 3 híbridos adicionales), que hacen un total de 826 taxa (Apéndice; Cuadro 1). Están repartidos en 560 con distribución conocida solo para el área (endémicos estrictos) y 165 que se presentan principalmente en el DCH y algunas poblaciones en localidades cercanas, que en este caso son denominados cuasi-endémicos. El DCH es una región ecológica principalmente árida con algunas zonas montañosas con tipos de vegetación asociados a climas templados y mayores precipitaciones. Existen 116 elementos asociados a estas comunidades y son aquí considerados como endemismos de ecosistemas no áridos.

El elemento endémico representa $24.87 \%$ de las aproximadamente 3382 especies de plantas vasculares descritas para esta región. De acuerdo con Rzedowski (1978, 1991a), en las zonas áridas y semiáridas de México se han descrito cerca de 6000 especies de plantas vasculares, de las cuales alrededor de $60 \%$ son restringidas, por lo tanto, en el DCH se encontraría $14 \%$ del total de la flora árida endémica. La cifra expuesta de endemismos en esta investigación es diferente a la propuesta de Rzedowski (1978), al indicar que el DCH contiene alrededor de 1000 especies y 16 géneros endémicos. Esta diferencia podría 
Cuadro 1: Participación cuantitativa de los grandes grupos de elementos vasculares endémicos al Desierto Chihuahuense.

\begin{tabular}{lccccc}
\hline Grupo taxonómico & Familias & Géneros & Especies & $\begin{array}{c}\text { Taxa } \\
\text { infraespecíficos }\end{array}$ & Híbridos \\
\hline Pteridophyta & 2 & 3 & 8 & 1 & 1 \\
Pinophyta & 2 & 2 & 2 & 1 & \\
Magnoliophyta & 1 & 1 & 3 & & \\
$\quad$ Magnolides & 7 & 27 & 56 & 7 & \\
Monocotiledóneas & 55 & 230 & 602 & 143 & 2 \\
$\quad$ Eudicotiledóneas & 67 & 263 & 671 & 152 & 3 \\
\hline Total & & & & & \\
\hline
\end{tabular}

deberse al concepto empleado de DCH por Rzedowski (1978), cuyo criterio de delimitación se basa principalmente en características morfotectónicas, haciéndolo de mayor extensión al considerado en este trabajo. Las causas de endemismo en el DCH son frecuentemente dadas por el hábitat, como es el caso de las especies halófilas y gipsófilas; por aislamiento como sucede con plantas que crecen sólo en las sierras de El Carmen, Jimulco, La Madera, Paila, Pico de Teyra y otras; por diversificación de taxa con muchas subpoblaciones en proceso de diferenciación, como en Echinocereus Engelm., Opuntia Desv., Perityle Benth., Thelocactus (K. Schum.) Britton \& Rose y Turbinicarpus (Backeb.) Buxb. \& Backeb., entre otras.

Las familias con mayor número de especies de distribución restringida se muestran en el Cuadro 2. Cactaceae y Asteraceae concentran aproximadamente 36\% del total de los elementos endémicos. Este resultado es similar al reportado para el Valle de Tehuacán-Cuicatlán (Méndez et al., 2004) y en el Desierto de San Felipe (Delgadillo y Macías, 2002), donde también son dominantes para la flora endémica. Cactaceae es la familia con mayor número de especies de distribución restringida, aunque la cifra en esta investigación es diferente a lo obtenido por Hernández et al. (2004), quienes reportan 229 especies limitadas a la región. La diferencia pudiera deberse a la extensión que consideran para el DCH la cual abarca parte del estado de Guanajuato y la zona árida Queretano-Hidalguense, haciéndolo de mayor extensión a los limites aquí contemplados.
Cuadro 2: Familias con mayor número de elementos endémicos y cuasi-endémicos del Desierto Chihuahuense. *Familias de Monocotiledóneas

\begin{tabular}{lclc}
\hline Familia & Especies & Familia & Especies \\
\hline Cactaceae & 141 & Euphorbiaceae & 21 \\
Asteraceae & 106 & Acanthaceae & 19 \\
Boraginaceae & 34 & *Asparagaceae & 20 \\
Brassicaceae & 31 & Caryophyllaceae & 16 \\
Fabaceae & 28 & Polygonaceae & 14 \\
*Poaceae & 25 & Solanaceae & 14 \\
Lamiaceae & 25 & Fagaceae & 10 \\
\hline
\end{tabular}

Se identificaron 263 géneros, de los cuales nueve tienen distribución restringida: Cumarinia Buxb., Emorya Torr., Gouldochloa Valdés-Reyna, Morden \& S.L. Hatch, Henricksonia B.L. Turner, Marshalljohnstonia Henrickson, Petrogenia I.M. Johnst., Plateilema (A. Gray) Cockerell, Psathyrotopsis Rydb. y Strotheria B.L. Turner. Los géneros con mayor número de elementos endémicos pertenecen al grupo de las eudicotiledóneas e integran 89.7\% del total (Cuadro 3). Tomando los datos de Hunt (1992), el DCH contiene $31.43 \%$ del total de cactáceas endémicas a México, además concentra $70.58 \%$ del total de endémicas del género Coryphantha (Engelm.) Lem. y 51.72\% de Echinocereus para México. Considerando estas cifras, 
más los reportes de Hernández y Godínez (1994) y Hernández et al. (2007), así como lo señalado por Carmona et al. (2008), el DCH se convierte en la región con mayor número de cactáceas endémicas a nivel nacional.

Cuadro 3: Géneros con mayor número de taxa endémicos al Desierto Chihuahuense.

\begin{tabular}{lclc}
\hline Género & Taxa & Género & Taxa \\
\hline Coryphantha (Engelm.) Lem. & 24 & Perityle Benth. & 14 \\
Echinocereus Engelm. & 16 & Nama L. & 12 \\
Mammillaria Torr. \& A. Gray & 15 & Escobaria Britton \& Rose & 10 \\
Turbinicarpus (Backeb.) & 15 & Quercus L. & 10 \\
$\quad$ Buxb. \& Backeb. & 14 & Salvia L. & 10 \\
Eriogonum Michx. & 14 & Thelocactus (K. Schum.) & 10 \\
Euphorbia L. & & Britton \& Rose & \\
& &
\end{tabular}

El matorral xerófilo es el tipo de vegetación con el mayor número de especies restringidas, seguidos en importancia por el matorral submontano (Cuadro 4). Las familias de angiospermas con mayor número de endemismos tienden a distribuirse en más de cinco tipos de vegetación. Boraginaceae, Brassicaceae, Cactaceae, Polygonaceae y Poaceae tienen presencia hasta en ocho tipos de vegetación y Asteraceae en 11 de las 14 unidades florísticas, mientras que los elementos de Chenopodiaceae y Scrophulariaceae son estrictamente de matorral halófilo y gipsófilo. Villarreal y Encina (2005) encuentran también la mayor concentración de endemismos para Coahuila en los matorrales xerófilo y submontano.

Se identificaron ocho formas de vida. La mayor participación la tienen las hierbas perennes (45.37\%), seguida por los arbustos suculentos (21.06\%) y arbustos (19.89\%), mientras que el $13.67 \%$ restante se encuentra repartido entre hierbas anuales, subarbustos, arborescentes, parásitas y saprófitas (Cuadro 5). Estos datos reflejan lo citado por Rzedowski (1991b), al considerar que las formas biológicas más ricas en endemismos a nivel nacional son las plantas herbáceas y arbustos.
Cuadro 4: Agrupación de los elementos endémicos por tipo de vegetación en el Desierto Chihuahuense.

\begin{tabular}{lc}
\hline Tipo de vegetación & Registros \\
\hline Bosque de coníferas & 10 \\
Bosque de encino & 24 \\
Bosque de juníperos & 2 \\
Bosque de oyamel & 2 \\
Bosque de pino & 7 \\
Bosque de pino piñonero & 22 \\
Bosque de pino-encino & 62 \\
Matorral halófilo y gipsófilo & 134 \\
Matorral submontano & 141 \\
Matorral xerófilo & 334 \\
Pastizal & 44 \\
Vegetación riparia & 15 \\
Vegetación subacuática & 1 \\
\hline
\end{tabular}

Cuadro 5: Cuantificación y proporción de endemismos para el Desierto Chihuahuense, en base a la forma biológica.

\begin{tabular}{lcc}
\hline Forma biológica & Número de taxa & Proporción de taxa \\
\hline Árbol & 8 & 1.17 \\
Arbusto & 135 & 19.89 \\
Arbusto suculento & 143 & 21.06 \\
Hierba anual & 60 & 8.83 \\
Hierba perenne & 308 & 45.37 \\
Parásita & 1 & 0.14 \\
Saprófita & 2 & 0.29 \\
Subarbusto & 22 & 3.24 \\
\hline
\end{tabular}

En la distribución por cuadrantes se encontró que la mayor proporción de taxa endémicos se localiza en el IV (36.64\%), seguidos del II (28.24\%), el III (19.84\%) y en menor proporción el I (15.26\%) (Figura 1). Los cuadrantes inferiores presentan mayores registros de elementos endémicos en una proporción de 56.48 a $43.5 \%$ en 
los superiores. La mayor concentración se presenta en los cuadrantes con orientación Este, en una proporción de $64.88 \%$ y los del Oeste con $35.12 \%$. Esto demuestra que la distribución de elemento endémico no es uniforme sobre la superficie del DCH, lo cual está en concordancia con Hernández et al. (2007) y Johnston (1974), que afirman que la flora endémica se distribuye de manera heterogénea, generando núcleos de alta diversidad.

Se obtuvieron 1467 presencias repartidas en los 10 estados que conforman el DCH. Coahuila, con 457 registros $(32.83 \%)$, presenta la mayor riqueza de endemismos, seguido por Texas con 218 (15.66\%), Chihuahua en tercer lugar con 179 (12.85\%), mientras que Arizona con solo 16 (1.14\%) presenta el número más bajo (Cuadro 6). La riqueza endémica de los estados no está determinada por la proporción territorial con la que participan en el DCH. Por ejemplo, la porción de Texas en el DCH es menor a la de Chihuahua; sin embargo, concentra mayor cantidad de endemismos. Un caso contrario pasa con Nuevo México, cuya porción en el DCH es mayor a la de Durango, Nuevo León, San Luis Potosí o Zacatecas, y tiene un número menor de endémicas. Nuevo León, con una superficie menor en el DCH en comparación con Durango, San Luis Potosí o Zacatecas, presenta un número más alto de endemismos.

Micro-endémica es aquella especie cuya área de distribución geográfica se restringe a una sola localidad. Este grupo representa en el DCH $28.27 \%$ de la flora endémica y está formado por 176 taxa, repartidos en 141 especies, 33 taxa infraespecíficos y dos híbridos. Las micro-endémicas se distribuyen en ocho de los diez estados que forman el DCH. Coahuila con 98 registros ocupa el primer lugar, seguido por Texas con 22 y finalmente Tamaulipas con tres especies en el último lugar (Cuadro 7). Por lo mencionado anteriormente, el número de micro-endemismos no es proporcional a la riqueza de endémicas por estado.

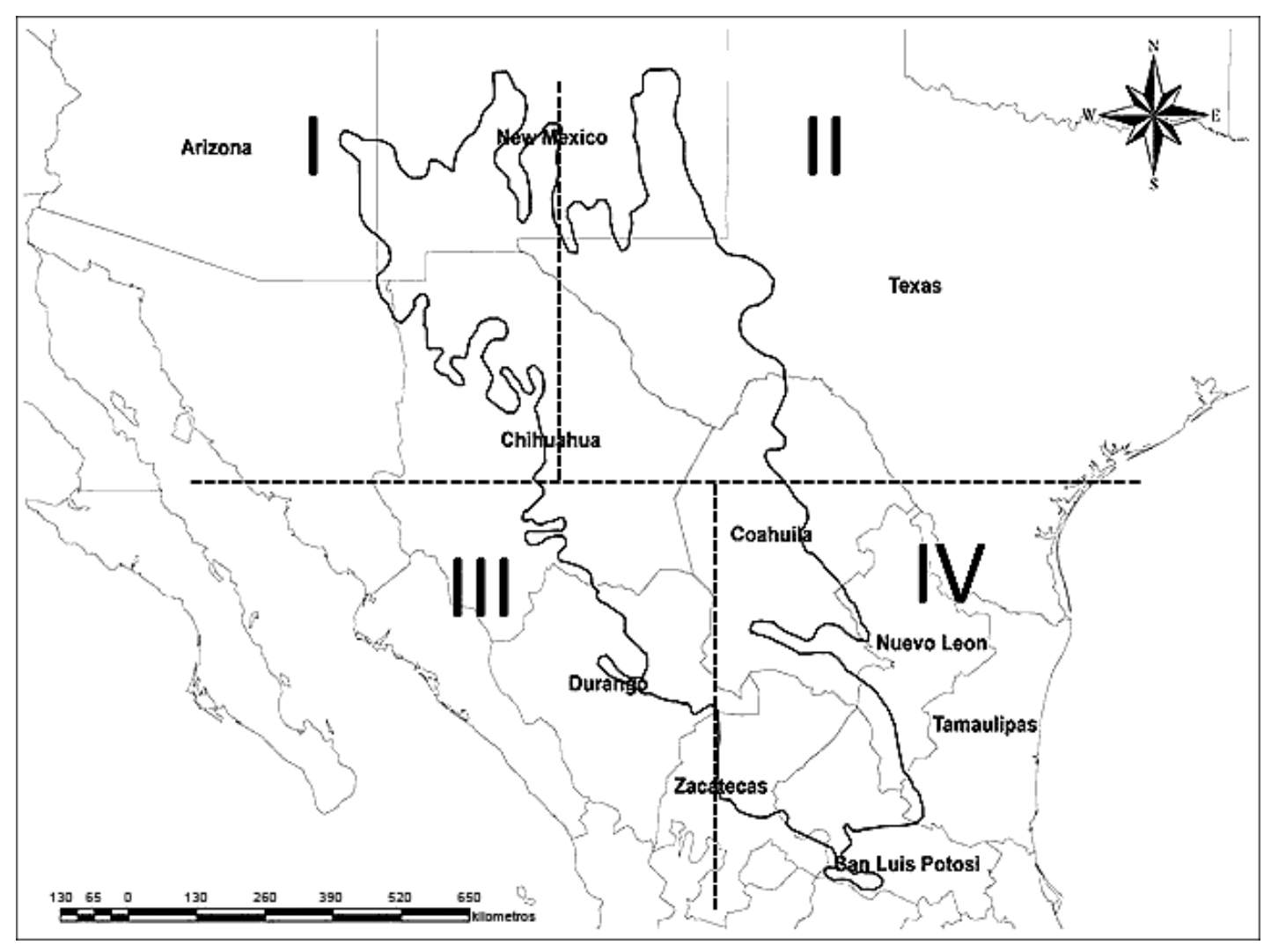

Figura 1: Ubicación de la región del Desierto Chihuahuense (de acuerdo con Johnston, 1974), y división en cuadrantes. 
Cuadro 6: Distribución por estados, su superficie y la presencia de endemismos en el Desierto Chihuahuense. *De acuerdo con Balleza y Villaseñor (2011).

\begin{tabular}{lcc}
\hline Estados & Superficie en el DCH $\left(\mathrm{km}^{2}\right)^{*}$ & Presencias \\
\hline Arizona & 14,353 & 16 \\
Chihuahua & 103,686 & 179 \\
Coahuila & 110,973 & 457 \\
Durango & 27,820 & 104 \\
Nuevo León & 15,355 & 142 \\
Nuevo México & 83,993 & 54 \\
San Luis Potosí & 33,892 & 103 \\
Tamaulipas & 3291 & 28 \\
Texas & 81,676 & 218 \\
Zacatecas & 29,961 & 91 \\
\hline
\end{tabular}

Cuadro 7: Distribución de micro-endémicos por estado en el Desierto Chihuahuense.

\begin{tabular}{lcc}
\hline Estado & $\begin{array}{c}\text { Número de elementos } \\
\text { micro-endémicos }\end{array}$ & $\begin{array}{c}\text { Proporción de } \\
\text { elementos micro- } \\
\text { endémicos }\end{array}$ \\
\hline Coahuila & 98 & 55.03 \\
Texas & 22 & 11.64 \\
San Luis Potosí & 19 & 8.99 \\
Chihuahua & 14 & 8.46 \\
Nuevo León & 13 & 4.76 \\
Durango & 10 & 5.82 \\
Zacatecas & 7 & 3.17 \\
Tamaulipas & 3 & 2.12 \\
\hline
\end{tabular}

De las zonas áridas y semiáridas de México, el $\mathrm{DCH}$ se ubica en la primera posición en concentración de especies endémicas, por encima del Desierto de Baja California (DBC) con 99 y del Desierto Sonorense (DS) con 137 elementos de diferencia. El DCH ocupa esta posición por su extensión, aunque el DBC es de menor superficie y alberga más endemismos que el DS. El DCH no posee tantos elementos endémicos por $\mathrm{km}^{2}$ como el
Valle de Tehuacán-Cuicatlán, que es una región con alta concentración de endemismos en una superficie pequeña (Cuadro 8).

Cuadro 8: Densidad y número de especies endémicas registradas para el Desierto Chihuahuense y algunas áreas fisiográficas y políticas. ${ }^{1}$ De acuerdo con Wiggins (1964), ${ }^{2}$ Wiggins (1980), ${ }^{3}$ Raven \& Axelrod (1978), ${ }^{4}$ Levin \& Moran (1989), ${ }^{5}$ De la Luz et al. (1995), ${ }^{6}$ Méndez et al. (2004), ${ }^{7}$ y ${ }^{9}$ Major (1988), ${ }^{8}$ Rzedowski (1991a).

\begin{tabular}{lrcc}
\hline Área & $\begin{array}{c}\text { Superficie } \\
\left(\mathrm{km}^{2}\right)\end{array}$ & $\begin{array}{c}\text { Especies } \\
\text { endémicas }\end{array}$ & Densidad \\
\hline Desierto Chihuahuense & 505,000 & 671 & 0.134 \\
Desierto Sonorense $^{1}$ & 310,000 & 512 & 0.165 \\
Desierto de Baja California $^{2}$ & 144,000 & 550 & 0.381 \\
Isla de Guadalupe $^{3}$ & 249 & 31 & 12.449 \\
Isla Revillagigedo $^{4}$ & 142 & 43 & 30.281 \\
El Vizcaíno $^{5}$ & $25,467.9$ & 37 & 0.145 \\
Valle de Tehuacán-Cuicatlán $^{6}$ & 8364.3 & 207 & 2.470 \\
Dakota del Sur $^{7}$ & 200,000 & 5 & 0.002 \\
Hawai $^{8}$ & 17,000 & 1610 & 9.470 \\
Utah $^{9}$ & 220,000 & 117 & 0.053 \\
\hline
\end{tabular}

Se contaron un total de 1467 registros distribuidos en 298 localidades, de las cuales 41 se consideran como sitios de gran diversidad endémica (Cuadro 9). En Coahuila las localidades con mayor concentración son: Cuatro Ciénegas (86 taxa), Sierras de Parras (69), La Paila (62), La Madera (51), El Carmen (42), Jimulco (37), Mojada (26), Viesca (27), Santa Rosa (23), Sierras del Pino (23), Las Delicias (21), Ocampo (14) y Sierra La Gavia (16). Texas, con casi la mitad de las localidades y presencias de Coahuila, muestra un arreglo muy localizado en su distribución más de $70 \%$ se concentra en la región de Trans-Pecos. Esta proporción se obtiene a partir de las presencias en las localidades que conforman esta región, como por ejemplo: Brewster (71), Culberson (14), El Paso (15), Hudspeth (10), Jeff Davis (8) y Presidio (37). 
Cuadro 9: Cuantificación de registros y localidades con endemismos por estados en el Desierto Chihuahuense.

\begin{tabular}{lcc}
\hline Estado & Número de registros & Número de localidades \\
\hline Arizona & 16 & 5 \\
Chihuahua & 179 & 55 \\
Coahuila & 457 & 77 \\
Durango & 104 & 17 \\
Nuevo León & 142 & 32 \\
Nuevo México & 54 & 19 \\
San Luis Potosí & 103 & 26 \\
Tamaulipas & 28 & 4 \\
Texas & 218 & 38 \\
Zacatecas & 91 & 20 \\
Áreas limítrofes & 75 & 5 \\
\hline
\end{tabular}

Los registros endémicos en Chihuahua se distribuyen de una forma más dispersa, alrededor de un tercio de las presencias se encuentran en tres localidades: Sierras Almagre (8), Santa Eulalia (9) y del Diablo (33). Para Nuevo León y San Luis Potosí cerca de 50\% de sus registros presentan una distribución concentrada en tres localidades: Galeana (54), Mina (18) y San Roberto (21) en Nuevo León, y El Huizache (4), Matehuala (29) y Sierra Catorce (13) en San Luis Potosí. Cincuenta y siete por ciento de los elementos endémicos en Durango presentan una distribución localizada a dos áreas: Sierra El Rosario (33) y Valle del Río Nazas (14). Cincuenta y un por ciento de los registros endémicos para Zacatecas se localizan en dos localidades: Concepción del Oro (41) y Mazapil (7). En Nuevo México se presenta un patrón similar, 48\% de sus endémicas se alberga en tres localidades: Otero (12), Doña Ana (9) y Eddy (11). En Tamaulipas la proporción de sus exiguos registros se concentran en Miquihuana (12) y Tula (9). Arizona no cuenta con áreas de alta riqueza endémica, no porque sus registros presenten una distribución muy dispersa, sino porque para el estado únicamente se tienen identificados 12 endemismos. Sin embargo, el Condado de Cochise presenta seis. Existen otras áreas que albergan una cantidad significativa de taxa endémicos, las cuales comparten territorios con dos o más áreas fisiográficas o políticas: Bolsón de Mapimí (45), Río Grande (17) y Sierra Hechiceros (22). En el Desierto Chihuahuense existen 24 áreas más significativas en elementos endémicos, en las cuales se concentran 900 registros, lo que equivale a $61.4 \%$ del total en el área (Cuadro 10).

Cuadro 10: Áreas del Desierto Chihuahuense con mayor número de endemismo. *Sitios considerados Área Natural Protegida, **Área Local Protegida.

\begin{tabular}{lclc}
\hline Área & Registros & Área & Registros \\
\hline *Cuatro Ciénegas & 86 & Sierra El Rosario & 33 \\
**Brewster & 71 & Matehuala & 29 \\
Sierra de Parras & 69 & **Viesca & 27 \\
Sierra La Paila & 62 & *Sierra Mojada & 26 \\
Galeana & 54 & Sierra del Pino & 23 \\
*Sierra La Madera & 51 & *Sierra Santa Rosa & 23 \\
*Bolsón de Mapimí & 45 & $*$ Sierra Las Delicias & 21 \\
*Sierra El Carmen & 42 & San Roberto & 21 \\
Concepción del Oro & 41 & Mina & 18 \\
Presidio & 37 & $*$ Big Bend & 17 \\
Sierra Jimulco & 37 & Sierra La Gavia & 16 \\
Sierra del Diablo & 33 & $* *$ Ocampo & 14 \\
\hline
\end{tabular}

Cerca de $50 \%$ de la flora endémica se resguarda en Áreas Naturales Protegidas, como son: Áreas de Protección de Flora y Fauna Maderas del Carmen, Cuatro Ciénegas, Cañón de Santa Elena, Sierra de Álamos y Ocampo, El Parque Nacional Big Bend y la Reserva de la Biosfera Mapimí. Como 50\% de la flora restante no se encuentra legalmente protegida como reserva natural, se recomienda que las acciones de conservación se refuercen y orienten a estos núcleos de diversidad endémica, o se establezcan otros en virtud de la riqueza florística de distribución restringida, tal como lo mencionan Villarreal y Encina (2005), para proteger al menos 48\% de los taxa 
endémicos del DCH. Dinerstein et al. (2000) proponen estas mismas áreas como reservas prioritarias de conservación para el DCH, por albergar especies de flora y fauna de distribución restringida y amenazada. Villarreal y Encina (2005) describen a las Sierras de Jimulco, Paila, Parras y Rosario como sitios de concentración endémica para la flora de Coahuila, las cuales deberían ser consideradas en proyectos de conservación. Esto coincide con el reporte de González et al. (2007), al declarar a la sierra El Rosario como un área biogeográfica y de alta endemicidad con necesidades de conservación.

\section{CONTRIBUCIONES DE AUTORES}

JAV, EEC y JAB concibieron y diseñaron el estudio. JAV y JAB realizaron los análisis. EEC, JAV, JAB, HRR y SJM contribuyeron a la adquisición de datos y la interpretación. JAB escribió el manuscrito con la ayuda de JAV y EEC. Todos los autores contribuyeron a la discusión, revisión y aprobación del manuscrito final.

\section{FINANCIAMIENTO}

Este estudio fue apoyado por la Universidad Autónoma Agraria Antonio Narro (proyecto 40012100/ Plantas endémicas y raras de Coahuila).

\section{AgRADECIMIENTOS}

A los revisores anónimos por su ayuda a la mejora de la presentación del escrito.

\section{LITERATURA CITADA}

Balleza, J. J. y J. L. Villaseñor. 2011. Contribución del estado de Zacatecas (México) a la conservación de la riqueza florística del Desierto Chihuahuense. Acta Botanica Mexicana 94: 61-89.

Carmona, M. P., R. Foroughbakhch, A. Flores, M. A. Alvarado y M. A.Guzmán. 2008. Flora cactológica y especies asociadas en el área natural protegida Sierra Corral de los Bandidos, Nuevo León, México. Revista Mexicana de Biodiversidad 79(2): 307-323.

Cloudsley, J. L. 1977. Man and the Biology of Arid Zones. University Park Press. Baltimore, USA. 255 pp.
CONABIO. 1998. La diversidad biológica de México: Estudio de País. Comisión Nacional para el Conocimiento y Uso de la Biodiversidad. México, D.F., México. 281 pp.

CONABIO. 1999. Ecorregiones de México, escala 1: 1,000,000. Comisión Nacional para el Conocimiento y Uso de la Biodiversidad. México, D.F., México.

De Candolle, A. P. 1820. Essai élémentaire de Géographie Botanique. In: Blanca, G. y F. Valle. 1986. Plantas endémicas de Andalucia Oriental. Monografias de flora y vegetación Bética 1: 1-53.

De la Luz, L., C. Coria y J. Cansino. 1995. Listados florísticos de México. XI. Reserva de la Biosfera El Vizcaíno, Baja California Sur. Instituto de Biología. Universidad Nacional Autónoma de México. México, D.F., México. $29 \mathrm{pp}$.

Delgadillo, J. y M. A.Macías. 2002. Componente florístico del desierto de San Felipe, Baja California, México. Boletín de la Sociedad Botánica de México 70: 45-65.

Delgadillo, C., J. L. Villaseñor y P. D. Dávila. 2003. Endemism in the Mexican flora: a comparative study in three plant groups. Annals of the Missouri Botanical Garden 90(1): 25-34. DOI: http://dx.doi.org/10.2307/3298523

Dinerstein, E., D. Olson, J. Atchley, C. Loucks, S. Contreras, R. Abell, E. Iñigo, E. Enkerlin, C. Williams y G. Castilleja. 2000. Ecoregion-Based Conservation in the Chihuahuan Desert. A Biological Assessment. World Wildlife Fund, Comisión Nacional para el Conocimiento y Uso de la Biodiversidad, The Nature Conservancy, Pronatura Noreste e Instituto Tecnológico y de Estudios Superiores de Monterrey. Washington, D.C., USA. 376 pp.

Espejo, A. 2012. El endemismo en las liliopsida mexicanas. Acta Botanica Mexicana 100: 195-257.

González, M. S., M. González, I. L. López, L. Reséndiz, J. A. Tena y F. I. Retana. 2011. El complejo Agave victoria-reginae (Agavaceae). Acta Botanica Mexicana 95: 65-94.

González, A., I. Luna, J. L. Villaseñor y C. A. Ruiz. 2007. Distributional patterns and conservation of species of Asteraceae endemic to eastern Mexico. Systematic Biodiversity 5: 135-144. DOI: http://dx.doi.org/10.1017/ S1477200006002192 
Henrickson, J. y M. C. Johnston. 2007. A flora of the Chihuahuan Desert Region. Published by J. Henrickson. Los Angeles, USA. 1695 pp.

Henrickson, J. y R. Straw. 1976. A gazetteer of the Chihuahuan Desert region. A supplement to the Chihuahuan Desert flora. In: Granados, D., A. Sánchez, R. L. Granados y A. Borja. 2011. Ecología de la vegetación del Desierto Chihuahuense. Revista Chapingo Serie Ciencias Forestales y del Ambiente 17: 111-130.

Hernández, H. M. y H. Godinez. 1994. Contribución al conocimiento de las cactáceas mexicanas amenazadas. Acta Botanica Mexicana 26: 33-52.

Hernández, H. M., C. Gómez y B. Goettsch. 2004. Checklist of Chihuahuan Desert Cactaceae. Harvard Paper Botany 9(1): 51-68.

Hernández, J. G., R. Chávez y E. Sánchez. 2007. Diversidad y estrategias para la conservación de cactáceas en el semidesierto Queretano. Biodiversitas 70: 6-9.

Hunt, D. 1992. CITES Cactaceae checklist. Royal Botanic Gardens, Kew. Surrey, UK. 190 pp.

IPNI. 2016. The International Plant Name Index. Publicado en internet http://www.ipni.org (consultado en febrero 2016).

Johnston, M. C. 1974. Brief of botanical, including vegetational, features of the Chihuahuan Desert Region with special emphasis on their uniqueness. In: Wauer, R. y D. Riskind (eds.). Transactions of the symposium on the biological resources of the Chihuahuan Desert Region, United States and Mexico. Sul Ross State University. Alpine, USA. Pp. 335-359.

Levin, G. y R. Moran. 1989. The vascular flora of Isla Socorro, Mexico. Memories of San Diego Society of Natural History 16: 1-71.

Major, J. 1988. Endemism: a botanical perspective. In: Myers, A. y P. Giller (eds.). Analytical Biogeography. Chapman and Hall. London, UK. 125 pp.

Medellín, F. 1982. The Chihuahuan Desert. In: Bender, G. (ed.). Reference handbook on the deserts of North America. Greenwood Press. Westport, USA. Pp. 321-372.

Méndez, I., E. Ortiz y J. L. Villaseñor. 2004. Las Magnoliophyta endémicas de la porción xerofítica de la provincia florística del Valle de Tehuacán-Cuicatlán, México. Anales del Instituto de Biología, Serie Botánica 75(1): 87-104.
Moore, M. 2014. The origin and evolution of gypsum endemic plants in the Chihuahuan Desert. Disponible en: http:// www.oberlin.edu/faculty/mmoore/gypsophily.html (consultado en octubre 2014).

Morafka, D. 1977. A biogeographical analysis of the Chihuahuan Desert through its herpetofauna. University of Southern California. Los Angeles, USA. 313 pp.

Muldavin, E. 2002. Some floristic characteristics of the northern Chihuahuan Desert: A search for its northern boundary. Taxon 51: 453-462.

Raven, P. y D. Axelrod. 1978. Origin and relationships of the California flora. University of California Publications in Botany 72: 1-134.

Rzedowski, J. 1978. Vegetación de México. Ed. Limusa. México, D.F., México. 5-6: 63-96.

Rzedowski, J. 1991a. Diversidad y orígenes de la flora fanerogámica de México. Acta Botanica Mexicana 14: 3-21.

Rzedowski, J. 1991b. El endemismo en la flora fanerogámica mexicana: una apreciación analítica preliminar. Acta Botanica Mexicana15: 47-64.

Sainz, H. y J.C. Moreno. 2002. Flora vascular endémica española. In: Pineda, F. D., J. M. de Miguel, M. A. Casado y J. Montalvo (eds.). La diversidad biológica Española. Ed. Pearson Educación. Madrid, España. 14: 175-195.

SEMARNAT. 2005. Biodiversidad. Secretaria de Medio Ambiente y Recursos Naturales. Disponible en http://app1. semarnat.gob.mx/dgeia/informe_04/04_biodiversidad/ index_biodiversidad.html (consultado en agosto 2013).

SEMARNAT. 2010. Norma Oficial Mexicana NOM-059SEMARNAT-2010. Protección Ambiental. Especies nativas de México de flora y fauna silvestres-Categorías de riesgo y especificaciones para su inclusión, exclusión o cambio-Lista de especies en riesgo. Diario Oficial de la Federación. Secretaria de Medio Ambiente y Recursos Naturales (SEMARNAT). México, D.F., México. 77 pp.

Schmidt, R. 1979. A climatic delineation of the "real" Chihuahuan Desert. Journal of Arid Environment 2: 243-250.

Shreve, F. 1942. The desert vegetation of North America. Botanical Review 8: 195-246. 
The Plant List. 2013. Version 1.1. Publicado en internet http:// www.theplantlist.org (consultado en noviembre 2013).

Tropicos. 2016. Tropicos, botanical information system at the Missouri Botanical Garden. Publicado en internet http:// www.tropicos.org (consultado en marzo 2016).

Villarreal, J. A. y J. A. Encina. 2005. Plantas vasculares endémicas de Coahuila y algunas áreas adyacentes, México. Acta Botanica Mexicana 70: 1-46.

Villaseñor, J. L. 1991. Las Heliantheae endémicas a México: una guía hacia la conservación. Acta Botanica Mexicana 15: 29-46.
Wiggins, I. 1964. Flora of the Sonoran Desert. In: Shreve, F. y I. Wiggins (eds.). Vegetation and flora of the Sonoran Desert. Stanford University Press. Stanford, USA. Pp. 189-1740.

Wiggins, I. 1980. Flora of Baja California. Stanford University Press. Stanford, USA. 1025 pp. 
Apéndice: Listado de elementos con distribución restringida al Desierto Chihuahuense.

Taxon endémico $(*)$, taxon cuasi-endémico $(* *)$, taxon endémico a la región pero de ambientes no áridos $(* * *)($ los taxa endémicos y cuasiendemicos pueden a su vez ser endémicos de ambientes no áridos). Se indica después del nombre de la familia el número estimado de especies para la familia, el número de taxa reportados para el DCH y el componente endémico de esa familia para el DCH (datos tomados de Henrickson y Johnston, 2007).

\section{PTERIDOPHYTA}

Pteridaceae (1100/52/4)

** Cheilanthes pinkavae T. Reeves. Hierba perenne. Matorral xerófilo. SE de Chih.; C y SO de Coah.; O y S de Tex.; N de Zac.

** Notholaena bryopoda Maxon. Hierba perenne. Matorrales submontano y xerófilo. E y C de Chih.; C y S de Coah.; C y S de N.L.

* Notholaena greggii (Kuhn) Maxon. Hierba perenne. Matorral xerófilo. Sierra Santa Eulalia, Chih.; Sierra La Paila y Viesca, Coah.; cerca de Cd. de Dgo.; SO de Galeana, N.L.; Río Grande, Presidio y Brewster Cos.; Tex.

** Notholaena neglecta Maxon. Hierba perenne. Matorral submontano. Montañas de Huachuca, Ariz.; Sierra Santa Eulalia, Chih.; Sierra Mojada, Coah.; Santa Catarina y Zaragoza, N.L.

Selaginellaceae $(675 / 15 / 5)$

* Selaginella carnerosana Reeves. Hierba perenne. Matorral submontano y bosque de pino piñonero. Sierra Carneros, Coah.

** Selaginella macrathera Weath. Hierba perenne. Bosque de encino y pastizal. Sierra El Virulento y S de Ojinaga, Chih.

** Selaginella mutica D.C. Eaton ex Underw. var. limitanea Weath. Hierba perenne. Matorral xerófilo. Paradise y Cochise Co., Ariz.; Luna y Doña Ana Cos., N.M., El Paso, Jeff Davis y Brewster Cos., Tex.

* Selaginella viridissima Weath. Hierba perenne. Matorral xerófilo y submontano. Sierras La Fragua, La Gloria y Mojada, Coah.; Montañas de Chisos, Tex.

** Selaginella $\mathrm{x}$ neomexicana Maxon. Hierba perenne. Matorral submontano. Paradise y Cochise Cos., Ariz.; Doña Ana Co., N.M.; El Paso, Presido, Val Verde y Brewster Cos., Tex.

\section{PINOPHYTA (GYMNOSPERMAE)}

\section{Cupressaceae (130/12/1)}

** Juniperus saltillensis M.T. Hall. Arbusto y árbol. Matorral submontano, bosque de pino y pastizal. Ojinaga, Chih.; Sierra de Parras y Saltillo, Coah.; Cerro El Potosí, N.L.; Melchor Ocampo, Zac.

Pinaceae $(250 / 16 / 1)$

*(***) Abies durangensis Martínez var. coahuilensis (I.M. Johnst.) Martínez. Árbol. Bosque de oyamel. Sierras La Madera, La Gloria, El Carmen, Santa Rosa y Serranías del Burro, Coah.

\section{MAGNOLIOPHYTA (ANGIOSPERMAS)}

\section{MAGNOLIDES}

Aristolochiaceae (450/2/3)

* Aristolochia coryi I.M. Johnst. Hierba perenne. Matorral xerófilo. Trans-Pecos, Presidio y Brewster Co., Tex.

* Aristolochia lassa I.M. Johnst. Hierba perenne. Matorral xerófilo. S de Coah.; C y S de N.L.; N y C de Zac.

* Aristolochia nana S. Watson. Hierba perenne. Matorral xerófilo. Guadalcazar, S.L.P

\section{MONOCOTILEDÓNEAS}

Amaryllidaceae (1500/16/2)

* Allium coryi M.E. Jones. Hierba perenne. Matorral xerófilo. Brewster, Jeff Davis y Presidio Cos., Tex.

*(***) Allium perdulce S.V. Fraser var. sperryi Ownbey. Hierba perenne. Matorral submontano. Brewster, Presidio, Jeff Davis y Reeves Cos., Tex.

Asparagaceae (530/57/20)

* Agave asperrima Jacobi subsp. maderensis (Gentry) B. Ullrich. Arbusto. Matorral submontano y bosque de pino. Sierra La Madera y Cuatro Ciénegas, Coah.

** Agave asperrima Jacobi subsp. zarcensis (Gentry) B. Ullrich. Arbusto. Matorral submontano y pastizal. Río Nazas, Dgo.

*(***) Agave havardiana Trel. Arbusto. Matorral submontano y bosque de coníferas. Sierra Rica y E de Los Huérfanos, Chih.; Sierras El Carmen, del Pino y Puerto Boquillas, Coah.; Montañas de Davis, Guadalupe y Chisos, NE de Marathon y Trans-Pecos, Tex.

** Agave nickelsii Rol.-Goss. Arbusto. Matorral xerófilo. Arteaga y Ramos Arizpe, Coah.

*(***) Agave parrasana A. Berger. Arbusto. Bosque de pino-encino. Sierras San Marcos, de Parras, La Madera, La Gavia y Cuatro Ciénegas, Coah.

* Agave striata Zucc. subsp. falcata (Engelm.) Gentry. Arbusto. Matorrales xerófilo y submontano. Sierras La Paila, La Madera y Encarnación, Rancho Nuevo y Saltillo, Coah.; cerca de Cd. de Dgo.; Dr. Arroyo, N.L.; Cedros y Mazapil, Zac.

** Agave victoriae-reginae T. Moore subsp. swobodae J.J. Halda. Arbusto. Matorrales xerófilo y submontano. San Pedro de las Colonias, Cerro de Las Noas, Coah.; Lerdo, Dgo. 
Apéndice: Continuación.

** Agave victoriae-reginae T. Moore subsp. victoria-reginae. Arbusto. Matorral xerófilo. Candela, Coah.; Cañón de la Huasteca y Parque Nacional Cumbres de Monterrey, N.L.

* Dandya purpusii (Brandegee) H.E. Moore. Hierba perenne. Matorral xerófilo. Sierra La Paila, Coah.

** Dasylirion cedrosanum Trel. Arbusto. Matorral xerófilo. Chih.; Coah.; Dgo.; N.L.; S.L.P.; Zac.

*(***) Dasylirion palaciosii Rzed. Arbusto. Matorral submontano. Guadalcazar, S.L.P.

* Manfreda brunnea (S. Watson) Rose. Arbusto. Matorral xerófilo. SE de Chih.; O y S de Coah.

* Manfreda potosina (B.L. Rob. \& Greenm.) Rose. Arbusto. Matorral xerófilo. Sierra de Parras, Coah.; San Miguel, Dgo.; Las Charcas, S.L.P.; Fresnillo, Zac.

*(***) Milla bryani I.M. Johnst. Hierba perenne. Matorral submontano. Sierra El Pulpito, Chih.; Cuatro Ciénegas, Ocampo y F.I. Madero, Coah.

*(***) Nolina arenicola Correll. Arbusto. Matorral submontano. Trans-Pecos, Tex.

** Yucca carnerosana (Trel.) McKelvey. Arbusto. Matorral xerófilo. Aldama y Ojinaga, Chih.; Coah.; N.L.; S.L.P.; Miquihuana, Tam.; $\mathrm{N}$ de Zac.

* Yucca endlichiana Trel. Arbusto. Matorral xerófilo. Sierras de Parras, El Rosario, La Paila y Estación Marte, Coah.

** Yucca linearifolia Clary. Arbusto. Matorral xerófilo. Sierra de Parras, Coah.; entre Galeana y Rayones, N.L.

* Yucca rigida (Engelm.) Trel. Arbusto. Matorral xerófilo. Jiménez, Chih.; Torreón y Viesca, Coah.; Bolsón de Mapimí y Tlahualilo, Dgo.

** Yucca faxoniana Sarg. Arbusto. Matorral xerófilo. Ojinaga, Chih.; Ocampo, Múzquiz y Acuña, Coah.

Commelinaceae (600/22/2)

* Tradescantia gypsophila B.L. Turner. Hierba perenne. Matorral halófilo y gipsófilo. Cuatro Ciénegas, Coah.

* Tradescantia wrightii Rose \& Bush. Hierba perenne. Matorral halófilo y gipsófilo. Sierra del Diablo, Chih.; Sierras El Carmen, Santa Rosa y Villa de Ocampo, Coah.

Cyperaceae (3800/55/3)

** Carex gypsophila Reznicek \& S. González. Hierba perenne. Matorral halófilo y gipsófilo. Aramberri y Galeana, N.L.

** Carex potosina Hemsl. Hierba perenne. Vegetación riparia. Saltillo, Coah.; El Canelito, N.L.; Matehuala, S.L.P.; Concepción del Oro, Zac.

$*(* * *)$ Cypringlea coahuilensis (Svenson) M.T. Strong. Hierba perenne. Bosque de pino-encino. Sierra La Fragua, Coah.

Orchidaceae $(20000 / 20 / 3)$

**(***) Hexalectris warnockii Ames \& Correll. Saprófita. Bosque de pino-encino. Montañas de Chiricahua, Ariz.; Sierra Los Órganos, Coah.; Montañas de Chisos, Davis y Vidrio, Tex.
*(***) Malaxis wendtii Salazar. Saprófita. Bosque de pino-encino. Sierras La Madera y El Carmen, Coah.

**(***) Mesadenus chiangii (M.C. Johnst.) Garay. Hierba perenne. Bosque de encino. Sierras Jimulco, La Paila, Coah.; N.L.

Poaceae (10000/308/25)

** Allolepis texana (Vasey) Soderstr. \& H.F. Decker. Hierba perenne. Matorral xerófilo. Coyame, Chih.; Torreón, Coah.; Hidalgo y Torreón de Cañas, Dgo.; Costa de Tam.; Trans-Pecos, Tex.

** Amelichloa clandestina (Hack.) Arriaga \& Barkworth. Hierba perenne. Matorral halófilo y gipsófilo, y pastizal. Arteaga, Ramos Arizpe y Saltillo, Coah.; San Roberto, N.L.; Matehuala, S.L.P.

* Blepharidachne bigelovii (S. Watson) Hack. Hierba perenne. Matorral halófilo y gipsófilo. Sierra de Parras, Coah.; Brewster, Culberson, El Paso, Pecos, Presidio y Terrell Cos., Tex.

** Bouteloua breviseta Vasey. Hierba perenne. Matorral halófilo, gipsófilo y submontano. Sierra del Diablo, Chih.; Sierra de Parras, Cuatro Ciénegas, Monclova, Ocampo, Ramos Arizpe, Saltillo, Castaños, Torreón y San Pedro, Coah.; Gómez Palacio, Dgo.; Dr. Arroyo, N.L.; Trans-Pecos, Tex.; Estación Camacho, Zac.

** Bouteloua chasei Swallen. Hierba perenne. Matorral halófilo y gipsófilo. Cerca de Agua Nueva, Coah.; Galeana y San Roberto, N.L.; Matehuala, S.L.P.

* Bouteloua chihuahuana (M.C. Johnst.) Columbus. Hierba perenne. Pastizal. Sierra Las Pampas, Chih.

* Bouteloua erecta (Vasey \& Hack.) Columbus. Hierba perenne. Matorral xerófilo. Ojinaga, Chih.; Ocampo y San Buenaventura, Coah.; Brewster y Presidio Cos., Tex.

* Bouteloua eriostachya (Swallen) Reeder. Hierba perenne. Matorral halófilo y gipsófilo, y pastizal. Sierras Las Cruces, La Fragua, Los Alamitos y Valle Buenavista, Coah.

* Bouteloua johnstonii Swallen. Hierba perenne. Matorral xerófilo. Sierras Los Órganos, La Fragua, La Paila, Las Delicias y Tanque La Luz, Coah.

* Bouteloua kayi Warnock. Hierba perenne. Vegetación riparia. Las Maravillas Creek, Negro Gap. y Brewster Co., Tex.

** Bouteloua warnockii Gould \& Kapadia. Hierba perenne. Matorral xerófilo. Castaños, San Pedro, Sierra de Parras, Coah.; Otero, N.M.; Trans-Pecos, Tex.

*(***) Bromus pinetorum Swallen. Hierba perenne. Bosque de pinoencino. Sierras del Pino y La Madera, Coah.

** Eragrostis erosa Scribn. ex Beal. Hierba perenne. Matorral xerófilo. Sierra El Presidio, Carrasco, Santo Domingo y La Alcaparra, Chih.; S del Salero, N.L.; Otero, N.M., Llera, Tam., Trans Pecos, Tex.

*(***) Festuca coahuilana Gonz.-Led. \& S.D. Koch. Hierba perenne. Bosque de coníferas. Sierras La Madera y La Concordia, Coah.; Tula, Tam. 
Apéndice: Continuación.

**(***) Festuca ligulata Swallen. Hierba perenne. Bosque de pinoencino. Sierras El Carmen, La Gloria y La Madera, Coah.; Cañón de Upper McKittrick, Montañas de Chisos y Guadalupe, Tex.

*(***) Gouldochloa curvifolia Valdés-Reyna, Morden \& S.L. Hatch. Hierba perenne. Bosque de pino piñonero. Cerca de Tula, Tam.

**(***) Melica montezumae Piper. Hierba perenne. Matorral submontano. Sierras San Martín, El Borracho, La Parra y Santa Eulalia, Chih.; Sierra Jimulco y Saltillo, Coah.; Culberson, Hudspeth, Pecos y Brewster Cos., Tex.

**(***) Muhlenbergia pubigluma Swallen. Hierba perenne. Matorral submontano y bosque de pino-encino. Cuatro Ciénegas, Sierra La Madera, Ramos Arizpe y Saltillo Coah.; Galeana y Zaragoza, N.L.

**(***) Muhlenbergia setifolia Vasey. Hierba perenne. Matorral submontano y bosque de pino-encino. Sierras El Presidio y Santo Domingo, Chih.; Sierras La Gavia, La Madera, del Pino y La cuesta El Plomo, Coah.; ANSM y MEXU; Chaves Co., N.M.

** Muhlenbergia villiflora Hitchc. Hierba perenne. Matorral halófilo y gipsófilo. Cerca de Ventura, El Fraile y Ocampo, Coah., San Roberto y Galeana, N.L.; Doña Ana Co., N.M.; Charcas y Matehuala, S.L.P.; Tula, Tam.; Presidio y Hudespeth Co., Tex.

*(***) Poa wendtii Soreng \& P.M. Peterson. Hierba perenne. Bosque de oyamel. Rincón de María y Sierra Santa Rosa, Coah.

* Sporobolus airoides (Torr.) Torr. subsp. regis (I.M. Johnst.) Wipff \& S.D. Jones. Hierba perenne. Matorral halófilo y gipsófilo. Laguna del Rey, Coah.

* Sporobolus coahuilensis Valdés-Reyna. Hierba anual. Matorral xerófilo. Sierra Las Delicias y Cuatro Ciénegas, Coah.; Brewster Co., Tex.

** Sporobolus palmeri Scribn. Hierba perenne. Matorral halófilo y gipsófilo. Saltillo, Coah.; cerca de Cd. de Dgo.; San Roberto, N.L.; Charcas, S.L.P.; Concepción del Oro, Zac.

** Sporobolus spiciformis Swallen. Hierba perenne. Matorral xerófilo. Bolsón de Mapimí, Chih.; Sierra Las Delicias, Cuatro Ciénegas, Arroyo Río Salado, Ramos Arizpe, Laguna del Rey y Viesca, Coah.; Bolsón de Mapimí, Dgo.; San Fernando, Tam.

Potamogetonaceae (100/8/1)

* Potamogeton clystocarpus Fernald. Hierba perenne. Vegetación riparia. Davis Co., Tex.

\section{EUDICOTILEDÓNEAS}

\section{Acanthaceae (2500/45/19)}

* Anisacanthus junceus (Torr.) Hemsl. Arbusto. Matorral xerófilo. Sierra Jimulco, Coah.; Concepción del Oro, Zac.

* Anisacanthus linearis (S.H. Hagen) Henrickson \& E.J. Lott. Arbusto. Matorral submontano. Sierras del Diablo y Hechiceros, Chih.;
Sierras La Paila, La Madera y del Pino, Coah.; límites con N.L.; Trans-Pecos, Presidio y Brewster Co., Tex.

* Anisacanthus puberulus (Torr.) Henrickson \& E.J. Lott. Arbusto. Matorral xerófilo. Sierra del Diablo, Chih.; Sierra de Parras, Coah.; Matehuala, S.L.P.; Montañas de Chinanti, Tex.; Pico de Teyra y Sierra de Guadalupe, Zac.

* Anisacanthus quadrifidus (Vahl) Nees var. potosinus Henrickson. Arbusto. Matorral submontano. Sierra Catorce, Matehuala y Bocas, S.L.P.; Concepción del Oro, Zac.

* Carlowrightia lesueurii Henrickson \& T.F. Daniel. Hierba perenne. Matorral xerófilo. Sierra Los Órganos, Chih.

* Carlowrightia mexicana Henrickson \& T.F. Daniel. Hierba perenne. Matorral xerófilo, rosetofilo y submontano. Cuatro Ciénegas, Sierras La Madera y Encantada, Coah.; Trans-Pecos, Tex.

* Carlowrightia ovata A. Gray. Hierba perenne. Matorral xerófilo. Cd. de Chih.

* Carlowrightia parvifolia Brandegee. Hierba perenne. Matorral xerófilo. Cuatro Ciénegas, Coah.; Trans-Pecos, Tex.

* Carlowrightia serpyllifolia A. Gray. Hierba perenne. Matorral xerófilo. Sierra del Diablo, Chih.; Sierras de Parras, Jimulco y Mojada, Coah.; Sierra El Rosario, Dgo.; Trans-Pecos, Tex.; Sierra Santa Rita, Zac.

* Holographis ilicifolia Brandegee. Arbusto. Matorral xerófilo. Sierra Jimulco y Cuatro Ciénegas, Coah.; Sierra El Rosario, Dgo.

* Justicia coahuilana T.F. Daniel. Hierba perenne. Matorral xerófilo. Cuatro Ciénegas, Coah.

* Justicia decurvata Hilsenb. Hierba perenne. Matorral submontano. Río Nazas, Dgo.

* Justicia henricksonii T.F. Daniel. Hierba perenne. Matorral xerófilo. Sierra del Pino, Coah.; Sierra El Astillero, Zac.

* Justicia warnockii B.L. Turner. Hierba perenne. Matorral xerófilo. Sierra Las Cruces, Coah.; Trans-Pecos, Tex.

* Mirandea grisea Rzed. Hierba perenne. Matorral xerófilo y submontano. Sierra Jimulco, Coah.; Sierra El Rosario, Dgo.; Matehuala, Guadalcázar y El Huizache, S.L.P.; Tula, Tam.

* Ruellia jimulcensis Villarreal. Hierba perenne. Matorral xerófilo. Sierra Jimulco, Coah.; Sierra El Rosario, Dgo.

* Ruellia parryi A. Gray. Arbusto. Matorral xerófilo. Meoquí, Chih.; Sierras de Parras, Mojada y La Gavia, Coah.; Galeana, N.L.; Montañas de Guadalupe y Eddy Co., N.M., Val Verde Co. y TransPecos, Tex.

* Siphonoglossa durangensis Henrickson \& Hilsenb. Hierba perenne. Matorral xerófilo. Río Nazas, Dgo.

* Stenandrium barbatum Torr. \& A. Gray. Hierba perenne. Matorral xerófilo. Sierra del Diablo y Ojinaga, Chih.; Sierras del Pino y Las Cruces, Coah.; Chaves Co., N.M. y Trans-Pecos, Tex. 
Apéndice: Continuación.

Amaranthaceae (900/37/6)

* Amaranthus acanthobracteatus Henrickson. Hierba anual. Matorral halófilo y gipsófilo. Bolsón de Mapimí, Chih.; Viesca, Coah.

* Tidestromia carnosa (Steyerm.) I.M. Johnst. Hierba anual. Matorral halófilo y gipsófilo. Ojinaga, Chih.; Saltillo, Coah.; Trans-Pecos, Presidio, Brewster y El Paso Co., Tex.

* Tidestromia rhizomatosa I.M. Johnst. Hierba perenne. Matorral halófilo y gipsófilo. Cuatro Ciénegas, Coah.

* Tidestromia suffruticosa (Torr.) Standl. var. coahuilana I.M. Johnst. Hierba perenne. Matorral xerófilo. Sierras Las Delicias, La Paila y del Pino, Coah.

* Tidestromia suffruticosa (Torr.) Standl. var. suffruticosa. Hierba perenne. Matorral xerófilo. General Cepeda y Ramos Arizpe, Coah.; Chaves Co., N.M. y Trans-Pecos, Tex.

* Tidestromia tenella I.M. Johnst. Hierba anual. Matorral xerófilo. Cuatro Ciénegas, Viesca y Mohovano, Coah.

Anacardiaceae (600/11/1)

*(***) Cotinus chiangii (D.A. Young) Rzed. \& Calderón. Arbusto. Matorral submontano. Sierra El Rosario, Dgo.

Apiaceae (3000/32/3)

*(***) Cymopterus filifolius (Mathias, Constance \& W.L. Theob.) B.L. Turner. Hierba perenne. Bosque de pino-encino. Montañas de TransPecos, Tex.

*(***) Donnellsmithia coahuilensis Mathias \& Constance. Hierba anual. Bosque de pino-encino. Sierra del Pino, Coah.

$* *(* * *)$ Villarrealia calcicola (Mathias \& Constance) G.L. Nesom. Hierba perenne. Matorral submontano y bosque de pino-encino. Sierras La Gloria, La Madera, La Gavia, San Marcos y SE de Monclova, Coah.

Apocynaceae (2000/26/5)

* Amsonia arenaria Standl. Hierba perenne. Matorral xerófilo. N de Chih.; S de Tex.

* Amsonia tharpii Woodson. Hierba perenne. Matorral xerófilo. TransPecos y Fort Stockton, Tex.

* Matelea chihuahuensis (A. Gray) Woodson. Hierba perenne. Matorral halófilo y gipsófilo. Sierra Hechiceros, Chih.

* Matelea texensis Correll. Hierba perenne. Matorral xerófilo y pastizal. Brewster Co., Tex.

**(***) Metastelma pringlei A. Gray. Hierba perenne. Matorral submontano. Sierras Hechiceros, del Diablo y Bolsón de Mapimí, Chih.; Sierras del Pino, La Madera, La Concordia, Mojada y Las Margaritas, Coah.; Bolsón de Mapimí, Dgo.; Tam.; Trans-Pecos, Tex.; N de Zac.

Asteraceae (30000/554/106)

*(***) Ageratina flourensifolia (B.L. Turner) R.M. King \& H. Rob. Arbusto. Matorral submontano y bosque de pino-encino. Sierras San Marcos y La Gloria, Coah.
*(***) Ageratina glischra (B.L. Rob.) R.M. King \& H. Rob. Arbusto. Matorral submontano y bosque de pino-encino. Sierras Jimulco, de Parras y La Madera, Coah.

* Ambrosia johnstoniorum Henrickson. Hierba perenne. Pastizal. Sierras Las Cruces y La Madera, Coah.

* Astranthium robustum (Shinners) De Jong. Hierba anual. Matorral xerófilo y submontano. Trans-Pecos, Tex.

** Aztecaster matudae (Rzed.) G.L. Nesom. Arbusto. Matorral xerófilo y pastizal. Sierras Carneros y Zapalinamé, Coah.; Iturbide y Rayones, N.L.; Sierra de Catorce, S.L.P.; Saín Alto, Zac.

* Bartlettia scaposa A. Gray. Hierba anual. Pastizal. Aldama, Laguna Las Palomas, Santa María y cerca de Cd. de Chih.; Sierras Jimulco y El Rosario, Dgo.; Hidalgo y Luna Co., N.M., Hudspeth Co., Tex.; Concepción del Oro, Zac.

* Brickellia glutinosa A. Gray. Arbusto. Matorral xerófilo. Sierra del Diablo, Chih.; Sierras Jimulco, Mojada y Cuatro Ciénegas, Coah.

*(***) Brickellia laccata Flyr. Arbusto. Matorral submontano. Sierra El Carmen, Coah.

*(***) Brickellia lemmonii A. Gray var. carmenensis B.L. Turner. Hierba perenne. Bosque de encino. Sierra El Carmen, Coah.

*(***) Brickellia stolonifera B.L. Turner. Hierba perenne. Bosque de coníferas. Sierra El Carmen, Coah.

*(***) Brickellia urolepis S.F. Blake. Hierba perenne. Bosques de pino-encino y encino. Sierras El Carmen, La Gavia, La Paila y La Madera, Coah.

* Calanticaria brevifolia (Greenm.) E.E. Schill. \& Panero. Arbusto. Matorral xerófilo. Bolsón de Mapimí, Chih.; Sierras Jimulco y de Parras, Coah.; Bolsón de Mapimí, Dgo.

* Calanticaria greggii (A. Gray) E.E. Schill. \& Panero. Arbusto. Matorral xerófilo y submontano y bosque de pino. Sierra de Parras, Cuatro Ciénegas, Ocampo y General Cepeda, Coah.; Galeana, N.L.; Sierra San Julian, Zac.

*(***) Chaetopappa hersheyi S.F. Blake. Hierba perenne. Matorral submontano. Eddy Co., N.M.; Montañas de Guadalupe y Culberson Co., Tex.

**(***) Chaetopappa parryi A. Gray. Hierba perenne. Matorral submontano y bosque de pino. Artega, Cuatro Ciénegas, Ramos Arizpe y Saltillo, Coah.; Aramberri, Dr. Arroyo y Galeana, N.L.

* Chaetopappa plomoensis B.L. Turner. Hierba perenne. Matorral xerófilo. Sierras El Carmen y Santa Rosa, Coah.

*(***) Chaetopappa pulchella Shinners. Hierba perenne. Matorral submontano. Sierra Almagre, Chih.; Sierra Mojada y Cuatro Ciénegas, Coah.

** Chromolaena bigelovii (A. Gray) R.M. King \& H. Rob. Arbusto. Vegetación riparia. Cuatro Ciénegas, Coah.; Aramberri, Bustamante, Galeana y Villaldama, N.L. 
Apéndice: Continuación.

* Erigeron bigelovii A. Gray. Hierba perenne. Matorral xerófilo y submontano. Sierra del Diablo, Chih.; Sierra de Parras, Cuatro Ciénegas, Ramos Arizpe y Ocampo, Coah.; Sierra El Rosario, Dgo.; Galeana, N.L., Trans-Pecos, Tex.; Concepción del Oro, Zac.

$*(* * *)$ Erigeron chiangii G.L. Nesom. Hierba perenne. Matorral submontano y bosque de encino. Sierra La Madera, Cuatro Ciénegas, Coah.

* Erigeron cuatrocienegensis G.L. Nesom. Hierba perenne. Matorral xerófilo. Cuatro Ciénegas, Coah.

* Erigeron heleniae G.L. Nesom. Hierba perenne. Matorral halófilo y gipsófilo. Mina, N.L.

* Flaveria intermedia J.R. Johnst. Hierba anual. Matorral gipsóilo. Yermo, NE de Dgo.

* Flaveria palmeri J.R. Johnst. Hierba anual. Matorral halófilo y gipsófilo. Bolsón de Mapimí, Coah.; Dgo.; S de N.L.

** Flourensia cernua DC. Arbusto. Matorral xerófilo. Ariz.; Chih.; Coah.; Hgo.; N.L.; N.M.; S.L.P.; Tex.; Zac.

* Flourensia dentata S.F. Blake. Arbusto. Matorral xerófilo. Río Nazas, Dgo.; Concepción del Oro, Zac.

* Flourensia ilicifolia Brandegee. Arbusto. Matorral submontano. Sierra de Parras, Coah.; Sierra El Sarnoso, Dgo.

*(***) Flourensia microphylla (A. Gray) S.F. Blake. Arbusto. Matorral submontano. Sierras Carneros, San Marcos y cerca de Saltillo, Coah.

*(**) Flourensia pulcherrima M.O. Dillon. Arbusto. Matorral submontano. Sierra del Diablo, Chih.; Sierra Jimulco, Coah.; Sierra El Rosario, Dgo.

*(***) Flourensia retinophylla Blake ex B.L. Rob. Arbusto. Matorral submontano. Sierras La Madera, La Paila, Las Delicias y Bolsón de Mapimí, Coah.

* Flourensia solitaria S.F. Blake. Arbusto. Matorral xerófilo. Cuatro Ciénegas, Coah.

**(***) Flyriella parryi (A. Gray) R.M. King \& H. Rob. Hierba perenne. Bosque de pino-encino. Cañón de Majalca, Chih.; Sierras de Coah.; N.L.; S de Tex.

* Gaillardia candelaria B.L. Turner var. candelaria. Hierba perenne. Matorral halófilo y gipsófilo. Sierra La Candelaria, Coah.

* Gaillardia candelaria B.L. Turner var. mikemoorei B.L. Turner. Hierba perenne. Matorral halófilo y gipsófilo. N de San Pedro de las Colonias, Coah.

* Gaillardia henricksonii B.L. Turner. Hierba perenne. Matorral halófilo y gipsófilo. Ocampo, Coah.

* Gaillardia powellii B.L. Turner. Hierba perenne. Matorral halófilo y gipsófilo. Cuatro Ciénegas, Escobedo, Valle de Hermanas y Monclova, Coah.

* Gaillardia turneri Averett \& A.M. Powell. Hierba perenne. Matorral xerófilo. Cerca del Rio Conchos, Chih.
*(***) Grindelia havardii Steyerm. Hierba perenne. Matorral submontano. Eddy Co., N.M.; Trans-Pecos y Crockett Co., Tex.

* Gundlachia triantha (S.F. Blake) Urbatsch \& R.P. Roberts. Subarbusto. Matorral xerófilo, halófilo y gipsófilo. Sierra Hechiceros y Bolsón de Mapimí, Chih.; O y C de Coah.; Lerdo, Dgo.; García, N.L.; Brewster, Tex.

** Gutierrezia grandis S.F. Blake. Hierba perenne. Bosques de pino piñonero y pino-encino. S de Coah.; Galeana, N.L.; Sierra Catorce, S.L.P.

* Haploesthes fruticosa B.L. Turner. Arbusto. Matorral xerófilo. Sierra La Paila, Coah.

* Haploesthes hintoniana B.L. Turner. Hierba perenne. Matorral halófilo y gipsófilo. N de San Pedro de las Colonias, Coah.

* Haploesthes robusta I.M. Johnst. Hierba perenne. Matorral halófilo y gipsófilo. Cuatro Ciénegas, Coah.

* Helianthus neglectus Heiser. Hierba anual. Vegetación riparia. Artesia, N.M.; Monahans y Ector Co., Tex.

* Helianthus paradoxus Heiser. Hierba anual. Vegetación riparia. Fort Stockton y Trans-Pecos, Tex.

* Henricksonia mexicana B.L. Turner. Hierba perenne. Matorral xerófilo. Sierra Jimulco, Coah.; Río Nazas, Dgo.

** Isocoma gypsophila B.L. Turner. Hierba perenne. Matorral halófilo y gipsófilo. San Roberto, Aramberri y Galeana, N.L.; Mazapil, Zac.

* Lepidospartum burgessii B.L. Turner. Arbusto. Matorral halófilo y gipsófilo. Dell City y Hudespeth Co., Tex.

* Leucosyris turneri (M.L. Arnold \& R.C. Jacks.) Pruski \& R.L. Hartm. Hierba anual. Matorral halófilo y gipsófilo. Meoqui, Chih.; Cuatro Ciénegas, Coah.

* Machaeranthera restiformis B.L. Turner. Subarbusto. Matorral halófilo y gipsófilo. Cuatro Ciénegas, Coah.

*(***) Marshalljohnstonia gypsophila Henrickson. Arbusto. Matorral submontano. Sierra Las Delicias, Coah.

* Nicolletia edwardsii A. Gray. Hierba perenne. Matorral xerófilo. Aldama y Jiménez, Chih., Coah.; Cuencamé, Dgo.; Trans-Pecos, Tex.; $\mathrm{N}$ de Zac.

*(***) Packera millelobata (Rydb.) W.A. Weber \& Á. Löve. Hierba perenne. Bosque de encino. Sierra Santa Eulalia, Chih.; Múzquiz y Ocampo, Coah.; Río Grande y Trans-Pecos, Tex.

** Parthenium argentatum A. Gray. Arbusto. Matorral xerófilo. Sierra Hechiceros, Chih.; Cuatro Ciénegas, Ocampo, Sierras Mojada y de Parras, Ramos Arizpe, Saltillo y Torreón, Coah.; Sierra El Rosario, Dgo.; Ixmiquilpan, Hgo.; Aramberrí y Galeana, N.L.; Matehuala, S.L.P.; Trans-Pecos, Tex.; Concepción del Oro, Zac.

* Parthenium rollinsianum Rzed. Hierba perenne. Matorral xerófilo y submontano. Cerca de Huizache y Guadalcázar, S.L.P.

* Pectis incisifolia I.M. Johnst. Hierba anual. Matorral xerófilo. Bolsón de Mapimí, Chih.; Coah.; Dgo. 
Apéndice: Continuación.

* Pectis pringlei Fernald. Hierba anual. Matorral xerófilo. S de Jiménez y La Cruz, Chih.; Sierra Jimulco, Coah.; Cuencamé, Dgo.

* Perityle bisetosa (Torr. ex A. Gray) Shinners var. appressa A.M. Powell. Hierba perenne. Matorral xerófilo. Brewster Co., Tex.

* Perityle bisetosa (Torr. ex A. Gray) Shinners var. scalaris A.M. Powell. Hierba perenne. Matorral xerófilo. Brewster Co., Tex.

*(**) Perityle bisetosa (Torr. ex A. Gray) Shinners var. spathulata A.M. Powell. Hierba perenne. Matorral submontano. Sierra El Carmen, Coah.

* Perityle carmenensis A.M. Powell. Hierba perenne. Matorral xerófilo. Sierra El Carmen, Coah.

*(***) Perityle castillonii I.M. Johnst. Hierba perenne. Matorral submontano. Sierra del Diablo, Chih.; Sierra Hechiceros y Ocampo, Coah.

*(***) Perityle coahuilensis A.M. Powell. Hierba perenne. Matorral submontano y bosque de encino. Sierra La Madera (El Sobaco), Coah.

* Perityle dissecta (Torr.) A. Gray. Hierba perenne. Matorral xerófilo. Manuel Benavides, Chih.; SO de Brewster y S de Presidio Cos., Tex.

*(***) Perityle fosteri A.M. Powell. Hierba perenne. Matorral submontano y bosque de pino-encino. Culberson Co., Tex.

*(***) Perityle huecoensis A.M. Powell. Hierba perenne. Matorral submontano y bosque de pino-encino. Montañas del N del Hueco y El Paso Co., Tex.

* Perityle parryi A. Gray. Hierba perenne. Matorral xerófilo. Cerca de Cd. de Chih.; Big Bend, Tex.

$*(* * *)$ Perityle rupestris (A. Gray) Shinners var. albiflora A.M. Powell. Hierba perenne. Matorral submontano. S de Brewster y NE de Presidio Co., Montañas de Davis y Trans-Pecos, Tex.

* Perityle rupestris (A. Gray) Shinners var. rupestris. Hierba perenne. Matorral xerófilo. Montañas de Davis, Tex.

* Perityle vaseyi J.M. Coult. Hierba perenne. Matorral halófilo y gipsófilo. Bolsón de Mapimi, Chih.; Cuatro Ciénegas Coah.; SO de Big Bend, Tex.

*(***) Perityle vitreomontana Warnock. Hierba perenne. Matorral submontano. Brewster Co., Tex.

$*(* * *)$ Pinaropappus mojadanus B.L. Turner. Hierba perenne. Matorral submontano. Sierra Mojada, Coah.

*(***) Pinaropappus parvus S.F. Blake var. parvus. Hierba perenne. Matorral submontano y bosque de pino-encino. Sierra del Diablo, Chih.; Montañas de Guadalupe, Culberson y Hudspeth Co., N.M. y Trans-Pecos, Tex.

$*(* * *)$ Pinaropappus powellii B.L. Turner. Hierba perenne. Bosque de pino-encino. Sierra La Encantada, Coah.

* Plateilema palmeri (A. Gray) Cockrell. Hierba anual. Matorral halófilo y gipsófilo. Cuatro Ciénegas y Saltillo, Coah.; Galeana, N.L.; Brewster, Co., Tex.
* Porophyllum amplexicaule Engelm. ex A. Gray. Hierba perenne. Matorral xerófilo. General Cepeda, Ramos Arizpe y Saltillo Coah.; Mina, Dr. Arroyo y Galeana, N.L.

* Porophyllum greggii A. Gray. Hierba perenne. Pastizal. Manuel Benavides y Ojinaga, Chih.; Sierra Las Cruces, Coah.; Trans-Pecos, Tex.

* Psathyrotopsis hintoniorum B.L. Turner. Hierba perenne. Matorral xerófilo. Sierra de Parras, Coah.

* Psathyrotopsis purpusii (Brandegee) Rydb. Hierba perenne. Matorral xerófilo. Sierra La Paila, Coah.

* Psathyrotopsis scaposa (A. Gray) H. Rob. Hierba perenne. Matorral xerófilo, halófilo y gipsófilo. N de Chih.; Bolsón de Mapimí, Dgo.; S de N.M.; Trans-Pecos, Brewster Co., Tex.

* Pseudoclappia arenaria Rydb. Arbusto. Matorral halófilo y gipsófilo. Cuatro Ciénegas, Coah.; Otero, N.M.; Trans-Pecos, Tex.

* Pseudoclappia watsonii A.M. Powell \& B.L. Turner. Arbusto. Matorral halófilo y gipsófilo. Trans-Pecos, Hudspeth y Jeff Davis Co., Tex.

* Sartwellia gypsophila A.M. Powell \& B.L. Turner. Hierba perenne. Matorral halófilo y gipsófilo. Ojinaga, Chih.; Presidio Co., Tex.

** Sartwellia mexicana A. Gray. Hierba anual. Matorral halófilo y gipsófilo. Cuatro Ciénegas, Coah.; Aramberri y Galeana, N.L.; Vanegas, S.L.P.; Concepción del Oro, Zac.

* Sartwellia puberula Rydb. Hierba anual. Matorral halófilo y gipsófilo. Bolsón de Mapimí, Chih.; Cuatro Ciénegas, Escobedo, Monclova, Ocampo, Sierra de Parras, Saltillo y Torreón, Coah.; Bolsón de Mapimí, Dgo.; Río Grande, Tex.

*(***) Senecio claryae B.L. Turner. Hierba perenne. Matorral submontano y bosque de encino. Sierra La Paila, Coah.

*(***) Senecio riskindii B.L. Turner \& T.M. Barkley. Hierba perenne. Bosque de coníferas. Sierra El Carmen, Serranías del Burro y Rancho El Bonito, Coah.

* Senecio warnockii Shinners. Hierba perenne. Matorral halófilo y gipsófilo. Culberson y Hudspeth Co., Tex.

* Solidago ericamerioides G.L. Nesom. Hierba perenne. Matorral halófilo y gipsófilo. Valle de Navidad, Galeana, N.L.

*(***) Stevia ovata Willd. var. texana Grashoff. Hierba perenne. Matorral submontano. Sierra del Pino, Coah.; Montañas de Chisos y Chinati, Tex.

* Strotheria gypsophila B.L. Turner. Hierba perenne. Matorral halófilo y gipsófilo. San Roberto y Galeana, N.L.

** Thelesperma scabridulum S.F. Blake. Hierba perenne. Matorral halófilo y gipsófilo. Cerca de Saltillo, Coah.; Galeana y cerca de Monterrey, N.L.

**(***) Thelesperma subaequale S.F. Blake. Hierba perenne. Bosque de encino. Sierras El Carmen, del Pino, Santa Rosa, Coah.; Santa Catarina y Villaldama, N.L. 
Apéndice: Continuación.

* Thymophylla gypsophila (B.L. Turner) Strother. Arbusto. Matorral halófilo y gipsófilo. Cuatro Ciénegas, Coah.

* Varilla mexicana A. Gray var. gypsophila B.L. Turner. Arbusto. Matorral xerófilo. Sierra de Parras, Cuatro Ciénegas, San Pedro de las Colonias, General Cepeda, Saltillo y Viesca, Coah.

* Varilla mexicana A. Gray var. mexicana. Arbusto. Matorral xerófilo. Sierra de Parras y Cuatro Ciénegas, Coah.; Cuencamé y Lerdo, Dgo.; Melchor Ocampo, Zac.

* Viguiera phenax S.F. Blake. Hierba anual. Matorral xerófilo y pastizal. O de El Piloncillo, Chih.; Sierra Las Cruces, Coah.; Sierra El Rosario, Dgo.; Trans-Pecos, Tex.

* Xanthisma pseudorestiforme B.L. Turner. Subarbusto. Matorral halófilo y gipsófilo. Mina, N.L.

* Xylorhiza wrightii (A. Gray) Greene. Hierba perenne. Matorral halófilo y gipsófilo. Bolsón de Mapimí, Chih.; Trans-Pecos, Tex.

** Xylothamia johnstonii G.L. Nesom. Arbusto. Matorral xerófilo. Guadalcázar y Santa María del Rio, S.L.P.

* Xylothamia parrasana (S.F. Blake) G.L. Nesom. Subarbusto. Matorral submontano. Sierra de Parras, Coah.; Melchor Ocampo, Zac.

** Xylothamia pseudobaccharis (S.F. Blake) G.L. Nesom. Subarbusto. Matorral xerófilo, halófilo y gipsófilo. Sierras La Paila, de Parras, Valle Seco y General Cepeda, Coah.

* Xylothamia purpusii (Brandegee) G.L. Nesom. Subarbusto. Matorral halófilo y gipsófilo. Bolsón de Mapimí, Chih.; Sierras del Pino y Mojada, Coah.; Bolsón de Mapimí, Dgo.

** Xylothamia riskindii (B.L. Turner \& G. Langford) G.L. Nesom. Subarbusto. Matorral halófilo y gipsófilo y bosque de pino-encino. Cerca de Saltillo, Coah.; Galeana, N.L.

* Xylothamia truncata G.L. Nesom. Hierba perenne. Matorral halófilo y gipsófilo. Cuatro Ciénegas, Coah.

* Zinnia oligantha I.M. Johnst. Hierba perenne. Matorral halófilo y gipsófilo. Bolsón de Mapimí, Chih.; El Toro cerca de Mohovano, Sierra Mojada y Laguna del Rey, Coah.

Berberidaceae (500/5/1)

* Berberis pinifolia (Lundell) C.H. Mull. var. coahuilensis C.H. Mull. Arbusto. Matorral xerófilo. Sierra La Madera, Coah.

Boraginaceae (2600/108/34)

* Antiphytum hintoniorum Higgins \& B.L. Turner. Hierba perenne. Matorral gipsófilo. Cerca de Galeana, N.L.

* Cryptantha cinerea (Greene) Cronquist. var. laxa (J.F. Macbr.) L.C. Higgins. Hierba perenne. Matorral xerófilo. El Paso del Norte, Chih.; Las Cruces, N.M.; Trans-Pecos, Tex.

* Cryptantha crassipes I.M. Johnst. Hierba perenne. Matorral xerófilo, halófilo y gipsófilo. Brewster Co., Tex.

* Cryptantha geohintonii B.L. Turner. Hierba anual. Matorral halófilo y gipsófilo. Mina, N.L.
* Cryptantha gypsites I.M. Johnst. Hierba perenne. Matorral halófilo y gipsófilo. Rancho El Aguililla y Pablillo, Galeana y E de San Roberto, N.L.

** Cynoglossum henricksonii L.C. Higgins. Hierba perenne. Matorral xerófilo. Sierra de Parras y Viesca, Coah.; Aramberri, Rancho El Aguililla, Galeana y Cerro el Potosí, N.L.; Mazapil, Zac.

* Heliotropium molle (Torr) I.M. Johnst. Hierba perenne. Matorral xerófilo. E de Chih.; Coah.; NE de Dgo.; S de Tex.

*(***) Lithospermum jimulcense I.M. Johnst. Hierba perenne. Matorral submontano y bosque de pino piñonero. Sierra Jimulco, Coah.

** Nama canescens C.L. Hitchc. Hierba perenne. Matorral halófilo y gipsófilo. Aramberri, Río de San José y Galeana, N.L.; Matehuala, S.L.P.; Concepción del Oro, Zac.

* Nama constancei J.D. Bacon. Hierba perenne. Matorral xerófilo. Sierra Los Órganos y Las Margaritas, Rancho El Coyote y Cuatro Ciénegas, Coah.

* Nama cuatrocienegensis G.L. Nesom. Hierba anual. Matorral halófilo y gipsófilo. Cuatro Ciénegas, Coah.

** Nama flavescens Brandegee. Hierba perenne. Matorral xerófilo. Sierra de Parras, Coah.; Aramberri y Galeana, N.L.

* Nama havardii A. Gray. Hierba anual. Matorral xerófilo. Sierra Hechiceros, Chih., Sierra Mojada, Coah.; Trans-Pecos, Tex.

* Nama johnstonii C.L. Hitchc. Hierba perenne. Matorral xerófilo y submontano. Sierras La Fragua, de Parras y Jimulco, Coah.

* Nama serpylloides A. Gray ex Hemsl. var. serpylloides. Hierba perenne. Matorral halófilo y gipsófilo. Cuatro Ciénegas y Valle de Hermanas al $\mathrm{N}$ de Monclova, Coah.

* Nama serpylloides A. Gray ex Hemsl. var. velutina C.L. Hitchc. Hierba perenne. Matorral halófilo y gipsófilo. Cuatro Ciéngas, Coah.

* Nama stenophylla A. Gray ex Hemsl. Hierba perenne. Matorral halófilo y gipsófilo. Bolsón de Mapimí, Chih.; Sierras del C y S de Coah., Mina, N.L.; Matehuala, S.L.P.

* Nama torynophylla Greenm. Hierba anual. Vegetación riparia. Sierra Hechiceros, Chih.; Sierra Mojada, Coah.; Big Bend, Tex.

** Nama turneri Bacon. Hierba perenne. Matorral halófilo y gipsófilo. San Roberto, N.L.; Matehuala y Camino a Los Cerritos, S.L.P.

** Nama xylopoda (Wooton \& Standl.) C.L. Hitchc. Hierba perenne. Matorral xerófilo. Montañas de Guadalupe, N.M.; Trans-Pecos, Tex.

* Omphalodes carranzae G.L. Nesom. Hierba perenne. Matorral xerófilo. Ocampo, Coah.

*(***) Omphalodes chiangii L.C. Higgins. Hierba perenne. Bosque de pino-encino. Sierras Santa Rosa y El Carmen, Coah.

*(***) Phacelia carmenensis B.L. Turner. Hierba anual. Bosque de encino. Sierra El Carmen, Coah.

* Phacelia gypsogenia I.M. Johnst. Hierba anual. Matorral halófilo y gipsófilo. Bolsón de Mapimí, Chih.; Ocampo, Coah.; Rancho El Aguililla y Santa Rita, N.L.; Concepción del Oro, Zac. 
Apéndice: Continuación.

* Phacelia hintoniorum B.L. Turner. Hierba anual. Matorral halófilo y gipsófilo. Rancho El Aguililla, Galeana, N.L.

** Phacelia infundibuliformis Torr. Hierba anual. Matorral xerófilo y submontano. Montañas Santa María, Ariz.; Sierra Almagre, Chih.; Sierras Mojada y Las Cruces, Coah.; N.M.; Trans-Pecos, Tex.; Concepción del Oro, Zac.

** Phacelia intermedia Wooton. Hierba anual. Matorral xerófilo. Deming y Río Grande, N.M.; Trans-Pecos y Brewster Co., Tex.

* Phacelia pallida I.M. Johnst. Hierba perenne. Matorral halófilo y gipsófilo. Sierras La Paila, Mojada y Las Magaritas, Cuatro Ciénegas, Coah.

* Phacelia petiolata I.M. Johnst. Hierba perenne. Matorral halófilo y gipsófilo. NE de Chih.; SO de Coah.; Brewster Co., Tex.

* Tiquilia gossypina (Wooton y Standl.) A.T. Richardson. Arbusto. Matorral halófilo y gipsófilo. E de Chih.; Coah.; N de Dgo.; TransPecos, Tex.

** Tiquilia greggii (Torr. \& A. Gray) A.T. Richardson. Arbusto. Matorral xerófilo, halófilo y gipsófilo. E de Chih.; Coah.; NE de Dgo.; O de N.L.; N.M.; N de S.L.P.; S de Tex.; N de Zac.

* Tiquilia mexicana (S. Watson) A.T. Richardson. Hierba perenne. Matorral xerófilo. E de Chih.; Coah.; O de N.L.; N de S.L.P.; TransPecos, Tex.; N de Zac.

* Tiquilia tuberculata A.T. Richardson. Hierba perenne. Matorral halófilo y gipsófilo. Mina, N.L.

* Tiquilia turneri A.T. Richardson. Hierba perenne. Matorral halófilo y gipsófilo. Cuatro Ciénegas, Coah.; Galeana, N.L.; Matehuala, S.L.P.

Brassicaceae (3000/125/31)

** Coelophragmus auriculatus (A. Gray.) O.E. Schulz. Hierba anual. Matorral xerófilo. Sierra del Diablo, Chih.; Sierra de Parras, Coah.; Sierra Santa Rita y Cerro el Potosí, N.L.; El Paso, Montañas Hueco y de Guadalupe, Tex.; Sierra El Astillero, Zac.

* Dryopetalon paysonii (Rollins) A.L.-Shehbaz. Hierba anual. Matorral xerófilo. Sierras de Parras y Jimulco y Torreón, Coah.

** Exhalimolobos parryi (Hemsl.) Al-Shehbaz \& C.D. Bailey. Hierba perenne. Matorral xerófilo. Cerca de Cd. de S.L.P.

*(***) Halimolobos diffusa (A. Gray) O.E. Schulz. Hierba perenne. Bosques de pino y pino-encino. Ariz.; Chih.; Coah.; N.M.; Tex.

** Halimolobos lasioloba O.E. Schulz. Hierba perenne. Matorral xerófilo. Cerca de Cd. de Chih.; Matehuala y Sierra Catorce, S.L.P.; Concepción del Oro, Zac.

* Mancoa henricksonii Rollins. Hierba anual. Matorral xerófilo. Pico de Teyra, Zac.

* Nerisyrenia castillonii Rollins. Subarbusto. Matorral halófilo y gipsófilo. Cuatro Ciénegas y Laguna del Rey, Coah.

** Nerisyrenia gracilis I.M. Johnst. Hierba perenne. Matorral halófilo y gipsófilo. Sierra La Paila y Saltillo, Coah.; Rancho El Aguililla,
Mina, San Roberto y Galeana, N.L.; Matehuala y Sierra Catorce, S.L.P.; Concepción del Oro y Mazapil, Zac.

* Nerisyrenia gypsophila J.D. Bacon. Subarbusto. Matorral halófilo y gipsófilo. Aldama y Ojigana, Chih.

* Nerisyrenia hypercorax Alexander \& M.J. Moore. Hierba perenne. Matorral gipsófilo. Otero y Chaves Co., N.M.

* Nerisyrenia incana Rollins. Subarbusto. Matorral halófilo y gipsófilo. Cuatro Ciénegas, Coah.

* Nerisyrenia johnstonii J.D. Bacon. Hierba perenne. Matorral halófilo y gipsófilo. Sierra Las Delicias, Coah.

* Nerisyrenia linearifolia (S. Watson) Greene var. baconiana (B.L. Turner) Henrickson. Hierba perenne. Matorral halófilo y gipsófilo. Sierra La Paila, SE de Coah.

** Nerisyrenia linearifolia (S. Watson) Greene var. mexicana J.D. Bacon. Hierba perenne. Matorral halófilo y gipsófilo. Cuatro Ciénegas, Coah.; San Roberto y Galeana, N.L.; Matehuala, S.L.P.; Miquihuana, Tam.

*(***) Physaria johnstonii (Rollins) O'Kane \& Al-Shehbaz. Hierba perenne. Bosque de pino-encino. Sierras El Carmen, del Pino y Santa Rosa, Coah.

*(***) Physaria mcvaughiana (Rollins) O'Kane \& Al-Shehbaz. Hierba perenne. Matorral submontano. Cuatro Ciénegas, Coah.; Trans-Pecos y Brewster Co., Tex.

**(***) Physaria mexicana (Rollins) O'Kane \& Al-Shehbaz. Hierba perenne. Matorral submontano. Sierra del Diablo, Chih.; Sierras de Menchaca, Santa Rosa, de Parras, El Carmen y La Encantada, Cuatro Ciénegas y Monclova, Coah.

*(***) Physaria wyndii (Rollins \& E.A. Shaw) O'Kane \& Al-Shehbaz. Hierba perenne. Bosque de pino-encino. Sierras El Carmen y Santa Rosa, Coah.

* Raphanorhyncha crassa Rollins. Hierba perenne. Pastizal. Bajío el Gringo, Chih.

* Rollinsia paysonii (Rollins) Al-Shehbaz. Hierba anual. Pastizal. Coah.; Dgo.

** Rorippa ramosa Rollins. Hierba perenne. Subacuática. E de Chih.; Sierra de Parras, Coah.; Ceballos, Dgo.; Brewster Co., Tex.

*(***) Scoliaxon mexicanus (S. Watson) Payson. Hierba perenne. Bosque de pino-encino. Sierra del Diablo, Chih.; Sierra de Parras, Coah.; Sierra Santa Rosa y Cerro Blanco, N.L.; Sierra El Astillero, Zac.

*(***) Sphaerocardamum compressum (Rollins) Rollins. Hierba perenne. Bosque de pino piñonero. Sierra de Parras, Coah.

*(***) Streptanthus cutleri Cory. Hierba anual. Matorral submontano. Sierra del Diablo, Chih.; Sierras Santa Rosa y El Carmen, Coah.; Big Bend, Tex. 
Apéndice: Continuación.

$*(* * *)$ Streptanthus platycarpus A. Gray. Hierba anual. Matorral submontano. Sierras Santa Rosa y El Carmen, Coah.; Brewster, Crockett, Culberson, Pecos, Presidio, Terrell y Val Verde Cos., Tex. *(***) Synthlipsis densiflora Rollins. Hierba perenne. Bosque de pinoencino. Sierra La Fragua y Cuatro Ciénegas, Coah.

* Synthlipsis greggi A. Gray. var. hispidula Rollins. Hierba anual. Matorral xerófilo. Cerca de Saltillo, Coah.; Galeana, Mina e Iturbide, N.L.; Montañas de San Miguelito, S.L.P.

*(***) Thelypodiopsis incisa Rollins. Hierba anual. Matorral submontano. Sierras La Gavia, San Marcos y cerca de Saltillo, Coah.

* Thelypodiopsis retrofracta (Rollins) Rollins. Hierba anual. Matorral xerófilo. Sierra de Parras, Coah.; Concepción del Oro, Zac.

**(***) Thelypodium longipes (Rollins) Rollins. Hierba anual. Matorral submontano. Sierras La Madera, de Parras y Jimulco, Coah.; Rayones, Mina y Galeana, N.L.

*(***) Thelypodium texanum (Cory) Rollins. Hierba anual. Matorral submontano. Brewster, Fresno Creek y Presidio Cos., Tex.

Buddlejaceae (150/5/2)

$*(* * *)$ Emorya rinconensis Mayfield. Subarbusto. Matorral submontano. Rancho el Rincón, entre Serranías del Burro Coah.; Big Bend, Tex.

**(***) Emorya suaveolens Torr. Arbusto. Matorral submontano y bosque de encino. Sierras La Madera, La Gavia, La Paila, La Fragua y de Parras, Acuña y Castaños, Coah.; San Roberto, N.L.; TransPecos, Tex.

Cactaceae (2000/202/141)

* Acharagma aguirreana (Glass \& R.A. Foster) Glass. Arbusto suculento. Matorral xerófilo. Sierras La Paila y San Marcos, Coah.

* Ancistrocactus scheeri (Salm-Dyck) Britton \& Rose. Arbusto suculento. Matorral xerófilo y bosque de pino-encino. Mina, N.L.; Meseta de Edwards, Kimble, Kinney, Real Uvalde y Val Verde Cos., Tex.

* Ariocarpus agavoides (Castañeda) E.F. Anderson. Arbusto suculento. Matorral xerófilo. Tula, Tam.

* Ariocarpus fissuratus (Engelm.) K. Schum. var. fissuratus. Arbusto suculento. Matorral xerófilo y bosque de pino piñonero. Río Grande, Chih.; Coah.; cerca de Bermejillo, Dgo.; Hudspeth, Presidio, Brewster, Trans-Pecos, Terrell y Val Verde Cos., Tex.

* Ariocarpus fissuratus (Engelm.) K. Schum. subsp. bravoanus (H.M. Hern. \& E.F. Anderson) Lüthy. Arbusto suculento. Matorral xerófilo. Microondas Nuñez, S.L.P.

* Ariocarpus fissuratus (Engelm.) K. Schum. subsp. hintonii (Stuppy \& N.P. Taylor) Halda. Arbusto suculento. Matorral xerófilo. Cerca de Vanegas, S.L.P.

* Ariocarpus fissuratus (Engelm.) K. Schum. subsp. lloydii (Rose) U. Guzmán. Arbusto suculento. Matorral xerófilo. Sierras La Paila y de Parras, Coah.; Hacienda de Cedros y Concepción del Oro, Zac.
** Ariocarpus kotschoubeyanus (Lem.) K. Schum. var. kotschoubeyanus. Arbusto suculento. Matorral xerófilo y pastizal. General Cepeda, Ramos Arizpe y Viesca, Coah.; Dr. Arroyo y Villa de García, N.L.; La Ventura, S.L.P.; Tula, Tam.; Sierra Guadalupe, Zac.

* Ariocarpus retusus Scheidw. Arbusto suculento. Matorral xerófilo. Sierra de Parras, Saltillo y Ramos Arizpe, Coah.; Dr. Arroyo, Galeana, Villa de García, Mier y Noriega, N.L.; cerca de Cd. de S.L.P.; Valle de Jaumave, Tam.; Hacienda de Cedros, Zac.

* Astrophytum capricorne (A. Dietr.) Britton \& Rose. Arbusto suculento. Matorral xerófilo. Cuatro Ciénegas, Ramos Arizpe y San Pedro, Coah.; Mina, N.L.

* Astrophytum myriostigma Lem. subsp. coahuilense (Moeller) Borg. Arbusto suculento. Matorral xerófilo. San Pedro de las Colonias, Coah.; cerca de Lerdo, Dgo.

* Corynopuntia aggeria (Ralston \& Hilsenb.) M.P. Griffith. Arbusto suculento. Matorral xerófilo. Valle El Sobaco, Coah.; Brewster Co., Tex.

* Corynopuntia bulbispina (Engelm.) F.M. Kunth. Arbusto suculento. Matorral xerófilo. General Cepeda, Coah.

* Corynopuntia grahamii (Engelm.) F.M. Kunth. Arbusto suculento. Matorral xerófilo. Coah.; Dgo.; N.M.; Tex.

* Corynopuntia moelleri (A. Berger) F.M. Kunth. Arbusto suculento. Matorral xerófilo. Cuatro Ciénegas, Coah.

* Corynopuntia schottii (Engelm.) F.M. Kunth. Arbusto suculento. Matorral xerófilo. Coah.; S de Tex.

* Corynopuntia vilis (Rose) F.M. Kunth. Arbusto suculento. Matorral xerófilo. S.L.P.; $\mathrm{N}$ de Zac.

* Coryphantha clavata Backeb. subsp. clavata. Arbusto suculento. Matorral xerófilo. Viesca, Coah.

* Coryphantha delaetiana A. Berger. Arbusto suculento. Matorral xerófilo. Coyame y Río Grande, Chih.; Cuatro Ciénegas y Estación Marte, Coah.; S de Cuencamé, Dgo.

* Coryphantha difficilis Orcutt. Arbusto suculento. Matorral xeróflio. Sierra La Paila, Coah.

* Coryphantha durangensis (Runge ex K. Schum.) Britton \& Rose. Arbusto suculento. Matorral xerófilo. San Pedro y Viesca, Coah.; Río Nazas, Dgo.

* Coryphantha echinus (Engelm.) Britton \& Rose. Arbusto suculento. Matorral xerófilo. Sierra Santa Elena, Chih.; Río Grande, Coah.; El Paso, Presidio, Trans-Pecos, NE de Howard y Coke Cos., Tex.

*(***) Coryphantha georgii Boed. Arbusto suculento. Bosque de pinoencino. La Ascensión, N.L.; Estación Villar, S.L.P.; Miquihuana, Tam.

* Coryphantha glanduligera Lem. Arbusto suculento. Matorral xerófilo. Dr. Arroyo, El Milagro y Los Pocitos, N.L.; Cerro el Calvario, Guadalcázar, El Huisache y Matehuala, S.L.P.; Tula, Tam. 
Apéndice: Continuación.

* Coryphantha gracilis Bremer \& A.B. Lau. Arbusto suculento. Matorral xerófilo y pastizal. NO de Hidalgo del Parral, Chih.

* Coryphantha hesteri Y. Wright. Arbusto suculento. Pastizal. Brewster Co., Tex.

* Coryphantha hintoniorum Dicht \& A. Lüthy. Arbusto suculento. Matorral xerófilo, halófilo y gipsófilo. Valle de Navidad y Galeana, N.L.

* Coryphantha longicornis Boed. Arbusto suculento. Matorral xerófilo. Cerca del Río Nazas, Dgo.

* Coryphantha macromeris (Engelm.) Lem. subsp. macromeris. Arbusto suculento. Matorral xerófilo. Bolsón de Mapimí, Chih.; Coah.; Bolsón de Mapimí, Dgo.; N.M.; Trans-Pecos, Tex.; Concepción del Oro, Zac.

* Coryphantha maiz-tablasensis O. Schwarz. Arbusto suculento. Matorral xerófilo, halófilo y gipsófilo. El Huisache, S.L.P.

* Coryphantha minima Baird. Arbusto suculento. Pastizal. Brewster Co., Tex.

* Coryphantha poselgeriana (A. Dietr.) Britton \& Rose. Arbusto suculento. Matorral xerófilo. SE de Jimenéz y Coyame, Chih.; Cuatro Ciénegas, Coah.; Cuencamé, Dgo.; N de S.L.P.; Montañas de Chisos, Tex.; Concepción del Oro, Zac.

* Coryphantha pseudoechinus Boed. subsp. laui (Bremer) Dicht \& A. Lüthy. Arbusto suculento. Matorral xerófilo. Sierra La Paila y Saltillo, Coah.

* Coryphantha pseudoechinus Boed. subsp. pseudoechinus. Arbusto suculento. Matorral xerófilo. Sierras San Marcos, La Paila y Cuatro Ciénegas, Coah.

* Coryphantha pulleineana (Backeb.) Glass. Arbusto suculento. Matorral xerófilo. S de Matehuala, S.L.P.

* Coryphantha ramillosa Cutak subsp. ramillosa. Arbusto suculento. Matorral xerófilo. Cuatro Ciénegas, Coah.; Terrell y Brewster Cos., Tex.

* Coryphantha ramillosa Cutak subsp. santarosa Dicht \& A. Lüthy. Arbusto suculento. Matorral xerófilo. Sierra La Babia, Coah.

** Coryphantha robbinsorum (W. Earle) A.D. Zimmerman. Arbusto suculento. Matorral xerófilo y submontano. Cochise Co., Ariz.; NE de Son.

* Coryphantha robustispina (Schott ex Engelm.) Britton \& Rose subsp. scheeri N.P. Taylor. Arbusto suculento. Matorral xerófilo. Cochise y Graham Cos., Ariz.; Hidalgo, Grant, Luna, Doña Ana y Sierra Cos., N.M.; El Paso Co., Tex.

* Coryphantha unicornis Boed. Arbusto suculento. Matorral xerófilo. Viesca, Coah.

* Coryphantha vogtherriana Werderm. \& Boed. Arbusto suculento. Matorral submontano. Cerca de Cd. de S.L.P.

* Coryphantha werdermannii Boed. Arbusto suculento. Matorral xerófilo. Sierra del Diablo, Chih.; Sierra La Paila, Coah.
* Cumarinia odorata (Boed.) Buxb. Arbusto suculento. Matorral xerófilo. La Ventura, S.L.P.; Miquihuana, Tam.

* Cylindropuntia anteojoensis (Pinkava) E.F. Anderson. Arbusto suculento. Matorral halófilo y gipsófilo. Sierra La Madera, Valle El Sobaco, Las Margaritas y Cuatro Ciénegas, Coah.

* Cylindropuntia imbricata (Haw.) F.M. Knuth subsp. argentea (M.S. Anthony) U. Guzmán. Arbusto suculento. Matorral xerófilo. Montañas del Mariscal y Big Bend, Tex.

* Cylindropuntia kleiniae (DC.) F.M. Knuth. Arbusto suculento. Matorral xerófilo. S de Coah.; N de Dgo.; C de N.L.; SE de N.M.; S de Tex.

* Echinocactus parryi Engelm. Arbusto suculento. Matorral xerófilo. Samalayuca, Chih.

* Echinocereus chisoensis W.T. Marshall subsp. chisoensis. Arbusto suculento. Matorral xerófilo. Big Bend y Brewster Co., Tex.

* Echinocereus chisoensis W.T. Marshall var. fobeanus (Oehme) N.P. Taylor. Arbusto suculento. Matorral xerófilo. Sierra de Parras, Coah.

* Echinocereus cinerascens (DC.) Lem. var. septentrionalis N.P. Taylor. Arbusto suculento. Matorral xerófilo. Cerca de Cd. de S.L.P.; Cd. de Zac.

* Echinocereus cinerascens (DC.) Lem. subsp. tulensis (Bravo) N.P. Taylor. Arbusto suculento. Matorral xerófilo. Huisache, S.L.P.; Miquihuana, Tam.

* Echinocereus davisii A.D. Houghton. Arbusto suculento. Matorral xerófilo y pastizal. Marathon y Brewster Cos., Tex.

* Echinocereus enneacanthus Engelm. var. enneacanthus. Arbusto suculento. Matorral xerófilo y pastizal. Sierra Hechiceros y San Miguel, Chih., Cuatro Ciénegas, Coah.; Cuencamé y Bermejillo, Dgo.; Dr. Arroyo, Mina, Villa de García, N.L.; Otero y Luna Co., N.M.; Matehuala, S.L.P.; Trans-Pecos y El Paso Co., Tex.

* Echinocereus nivosus Glass \& R.A. Foster. Arbusto suculento. Bosque de pino piñonero y pastizal. Sierra de Parras, Coah.

* Echinocereus longisetus (Engelm.) Lem. subsp. delaetii N.P. Taylor. Arbusto suculento. Bosques de encino y pino piñonero y pastizal. Sierras La Paila y San Marcos, Coah.

$*(* * *)$ Echinocereus longisetus (Engelm.) Lem. subsp. longisetus. Arbusto suculento. Bosque de pino-encino. Sierras La Madera y El Carmen, Coah.

* Echinocereus primolanatus Fritz Schwarz ex N.P. Taylor. Arbusto suculento. Matorral xerófilo. Sierras La Paila y Los Alamitos, Coah. ** Echinocereus stramineus (Engelm.) F. Seitz subsp. stramineus. Arbusto suculento. Matorral xerófilo. N de Chih.; S de Coah.; Sierra El Rosario, Dgo.; N.L.; Eddy, Otero y Doña Ana Cos., N.M.; Matehuala, S.L.P.; Trans-Pecos, Tex.; Concepción del Oro, Zac.

* Echinocereus viridiflorus Engelm. subsp. chloranthus N.P. Taylor. Arbusto suculento. Matorral xerófilo y submontano y pastizal. Cerca 
Apéndice: Continuación.

de Cd. Juaréz, Chih.; Doña Ana, Otero y Eddy Cos., N.M.; El Paso, Culberson, Hudspeth, Cos., Tex.

* Echinocereus viridiflorus Engelm. subsp. correllii (L.D. Benson) W. Blum \& Mich. Lange. Arbusto suculento. Pastizal. Brewster y Marathon, Cos., Tex.

* Echinocereus viridiflorus Engelm. subsp. cylindricus N.P. Taylor. Arbusto suculento. Bosque de encino y pastizal. Sierra de Hechiceros, Chih.; Eddy, Chaves, Otero, Lincoln y Doña Ana Cos., N.M.; Montañas de Davis, Tex.

* Echinomastus intertextus (Engelm.) Britton \& Rose subsp. dasyacanthus (Engelm.) U. Guzmán. Arbusto suculento. Matorral xerófilo. Sierra Hechiceros, Chih.; Sierra de Hechiceros, Coah., N.M.; Trans-Pecos, Tex.

** Echinomastus mariposensis Hester. Arbusto suculento. Matorral xerófilo y pastizal. Cuatro Ciénegas, General Cepeda, Escobedo y Monclova, Coah.; Presidio y Brewster Cos., Tex.

* Echinomastus unguispinus (Engelm.) Britton \& Rose subsp. laui (G. Frank \& Zecher) Glass. Arbusto suculento. Matorral xerófilo y pastizal. Charcas, S.L.P.; cerca de Salinas, Zac.

* Echinomastus unguispinus (Engelm.) Britton \& Rose subsp. unguispinus. Arbusto suculento. Matorral xerófilo y pastizal. Jiménez, Chih.; Sierra La Paila, Coah.; Sierra El Rosario, Dgo.; Concepción del Oro, Zac.

* Echinomastus warnockii (L.D. Benson) Glass \& R.A. Foster. Arbusto suculento. Matorral xerófilo y pastizal. Ojinaga, Chih.; Sierra Santa Rosa, Coah.; Hudspeth, Culberson, Presidio y Brewster Cos., Tex.

* Epithelantha cryptica D. Donati \& C. Zanovello. Arbusto suculento. Matorral xerófilo. La Muralla, Coah.

* Epithelantha micromeris (Engelm.) F.A.C. Weber ex Britton \& Rose subsp. greggii (Engelm.) N.P. Taylor. Arbusto suculento. Matorral xerófilo. Sierras de Parras y La Paila, Coah.

$*(* * *)$ Epithelantha micromeris (Engelm.) F.A.C. Weber ex Britton \& Rose subsp. pachyrhiza (W.T. Marshall) N.P. Taylor. Arbusto suculento. Matorral submontano. Saltillo, Coah.

* Epithelantha micromeris (Engelm.) F.A.C. Weber ex Britton \& Rose subsp. bokei (L.D. Benson) U. Guzmán. Arbusto suculento. Matorral xerófilo y submontano. Sierra La Paila y Cuatro Ciénegas, Coah.; Big Bend y Río Grande, Tex.

* Epithelantha micromeris (Engelm.) F.A.C. Weber ex Britton \& Rose subsp. Polycephala (Backeb.) Glass. Arbusto suculento. Matorral xerófilo. Ramos Arizpe y Saltillo, Coah.

* Escobaria chihuahuensis Britton \& Rose. Arbusto suculento. Matorral xerófilo. Cerca de Cd. de Chih. y Rosales, Chih.

*(***) Escobaria dasyacantha (Engelm.) Britton \& Rose subsp. chaffeyi (Britton \& Rose) N.P. Taylor. Arbusto suculento. Bosque de encino. Sierras La Madera y La Paila, Coah.; Sierra El Rosario,
Dgo.; Sierra Catorce, S.L.P.; Montañas de Chisos, Tex.; Concepción del Oro, Zac.

* Escobaria dasyacantha (Engelm.) Britton \& Rose subsp. dasyacantha. Arbusto suculento. Matorral xerófilo y pastizal. Sierra Santa Elena, Chih.; El Paso, Hudspeth, Jeff Davis, Trans-Pecos, Presidio y Brewster Cos., Tex.

* Escobaria duncanii (Hester) Backeb. Arbusto suculento. Matorral xerófilo. Sierra Co., N.M.; Brewster y Presidio Cos., Tex.

* Escobaria henricksonii Glass \& Foster. Arbusto suculento. Matorral xerófilo. Sierra del Diablo, Chih.; Sierra El Rosario, Dgo.

* Escobaria laredoi (Glass \& Foster) N.P. Taylor. Arbusto suculento. Matorral xerófilo. Sierra de Parras, Coah.

* Escobaria lloydii Britton \& Rose. Arbusto suculento. Matorral xerófilo. Sierra de Zuluaga y Concepción del Oro, Zac.

* Escobaria orcuttii (Boed.). Arbusto suculento. Matorral xerófilo. Cochise Co., Ariz.; Hidalgo, Grant y Luna Cos., N.M.

* Escobaria sneedii Britton \& Rose subsp. sneedii. Arbusto suculento. Matorral xerófilo. Eddy Co. y NE de Guadalupe, N.M.

* Escobaria zilziana Backeb. Arbusto suculento. Matorral xerófilo. Cuatro Ciénegas, Coah.; Río Nazas, Dgo.

** Ferocactus hamatacanthus (Muehlenpf.) Britton \& Rose subsp. hamatacanthus. Arbusto suculento. Matorral xerófilo y bosque de pino-encino. Chih.; Coah.; Sierra El Rosario, Dgo.; N.L.; Montañas de Cornudas, N.M.; Sierra Guadalupe, S.L.P.; Montañas de Davis, Tex.; Concepción del Oro, Zac.

** Ferocactus pilosus (Galeotti) Werderm. Arbusto suculento. Matorral xerófilo y bosque de pino. Sierras La Madera y del Pino, Coah.; Sierra El Rosario, Dgo.; Aramberri, Dr. Arroyo, Santa Catarina, Galeana y Villa de García, N.L.; Matehuala, S.L.P.; Miquihuana, Tam.; Concepción del Oro, Zac.

* Glandulicactus uncinatus (Galeotti ex Pfeiff.) Backeb. subsp. uncinatus. Arbusto suculento. Matorral xerófilo. El Huizache, S.L.P.

* Grusonia bradtiana (J.M. Coult.) Britton \& Rose. Arbusto suculento. Matorral xerófilo. Bolsón de Mapimí, Chih.; Bolsón de Mapimí, Sierra La Paila y Laguna del Rey, Coah.; Bolsón de Mapimí, Dgo.

* Leuchtenbergia principis Hook. Arbusto suculento. Matorral xerófilo. Sierras La Paila, de Parras y Saltillo, Coah.; Río Nazas, Dgo.; Mier y Noriega, N.L.; Matehuala, S.L.P.

* Mammillaria aureilanata Backeb. Arbusto suculento. Matorral xerófilo. Entre El Huisache y la Cd. de S.L.P., S.L.P.

* Mammillaria carretii Rebut ex K. Schum. Arbusto suculento. Matorral xerófilo. Saltillo y Ramos Arizpe, Coah.; Villa de García, N.L.

* Mammillaria coahuilensis (Boed.) Moran subsp. albiarmata (Boed.) D.R. Hunt. Arbusto suculento. Matorral xerófilo. Saltillo y Viesca, Coah.

* Mammillaria coahuilensis (Boed.) Moran subsp. coahuilensis. Arbusto suculento. Matorral halófilo y gipsófilo. Viesca, Coah. 
Apéndice: Continuación.

* Mammillaria chionocephala J.A. Purpus. Arbusto suculento. Matorral xerófilo. Sierras de Parras, La Madera, La Paila y Saltillo, Coah.

* Mammillaria grusonii Runge. Arbusto suculento. Matorral xerófilo. Cuatro Ciénegas y San Pedro, Coah.; NE de Dgo.

* Mammillaria guelzowiana Werderm. Arbusto suculento. Pastizal. Río Nazas, Dgo.

** Mammillaria lasiacantha Engelm. Arbusto suculento. Matorral xerófilo. Chih.; Cuatro Ciénegas y Saltillo, Coah.; Río Nazas, Dgo.; Otero y Luna Co., N.M., Sierra Catorce, S.L.P., NO de Son., TransPecos, Tex. y Concepción del Oro, Zac.

** Mammillaria lenta K. Brandegee. Arbusto suculento. Matorral xerófilo. Viesca, Coah.; Monterrey, N.L.

* Mammillaria pachycylindrica Backeb. Arbusto suculento. Matorral xerófilo. Cuencamé, Dgo.

* Mammillaria parrasensis Repp. Arbusto suculento. Matorral xerófilo. Sierra de Parras, Coah.

* Mammillaria pennispinosa Krainz subsp. nazasensis (Glass \& R.A. Foster) D.R. Hunt. Arbusto suculento. Matorral xerófilo. Río Nazas, Dgo.

* Mammillaria pennispinosa Krainz subsp. pennispinosa. Arbusto suculento. Matorral xerófilo. Bolsón de Mapimí, Chih.; Coah.; Dgo.

* Mammillaria pottsii Scheer ex Salm-Dyck. Arbusto suculento. Matorral xerófilo. Chih.; S de Coah.; Cuencamé, Dgo.; Villa de García, N.L.; Brewster y Presidio, Cos., Tex.; Fresnillo, Zac.

* Mammillaria stella-de-tacubaya Heese. Arbusto suculento. Matorral xerófilo. Bolsón de Mapimí y Viesca, Coah.; Río Nazas, Dgo.

* Neolloydia matehualensis Backeb. Arbusto suculento. Matorral xerófilo. Cerca de Dr. Arroyo, N.L.; cerca de Matehuala, S.L.P.

* Opuntia atrispina Griffiths. Arbusto suculento. Matorral xerófilo. N de Coah.; S de Tex.

* Opuntia aureispina (S. Brack \& K.D. Heil) Pinkava \& B.D. Parfitt. Arbusto suculento. Matorral xerófilo. Sierra El Carmen, Coah.; Big Bend, Río Bravo y Brewster Co., Tex.

* Opuntia chaffeyi Britton \& Rose. Arbusto suculento. Matorral halófilo y gipsófilo. Mazapil, Zac.

* Opuntia chisosensis (M.S. Anthony) D.J. Ferguson. Arbusto suculento. Matorral xerófilo. N de Coah.; S de Tex.

** Opuntia engelmannii Salm-Dyck ex Engelm. subsp. cuija Griffiths \& Hare. Arbusto suculento. Matorral xerófilo. S de Coah.; Hgo.?; S.L.P.; Zac.

* Opuntia engelmannii Salm-Dyck ex Engelm. subsp. rastrera (F.A.C. Weber) Pinkava. Arbusto suculento. Matorral xerófilo y pastizal. Coah.; N.L.; S.L.P.; Zac.

* Opuntia megarhiza Rose. Arbusto suculento. Matorral xerófilo. S.L.P.
* Opuntia pailana Weing. Arbusto suculento. Matorral xerófilo. Sierra La Paila, Coah.

* Opuntia x carstenii R. Puente \& C. Hamann. Arbusto suculento. Matorral xerófilo. Cerca de Saltillo, Coah.

* Opuntia x spinosibacca M.S. Anthony. Arbusto suculento. Matorral xerófilo. Big Bend, Tex.

* Opuntia strigil Engelm. Arbusto suculento. Matorral xerófilo. S de Tex.

* Pelecyphora aselliformis Ehrenb. Arbusto suculento. Pastizal. Entre El Huisache y la Cd. de S.L.P.

* Pelecyphora strobiliformis Frić \& Schelle. Arbusto suculento. Matorral xerófilo. Dr. Arroyo, N.L.; Miquihuana, Tam.

$*(* * *)$ Stenocactus boedekerianus (A. Berger) A.W. Hill. Arbusto suculento. Bosque de pino piñonero. Concepción del Oro, Zac.

* Stenocactus multicostatus (Hildm.) A. Berger ex A.W. Hill subsp. multicostatus. Arbusto suculento. Matorral xerófilo y pastizal. Bolsón de Mapimí, Chih.; Coah.; Dgo.

*(***) Stenocactus multicostatus (Hildm.) A. Berger ex A.W. Hill subsp. zacatecasensis (Britton \& Rose) U. Guzmán \& Vazq.-Ben. Arbusto suculento. Bosque de pino piñonero. Cerca de Cd. de Zac.

* Thelocactus bicolor (Galeotti ex Pfeiff.) Britton \& Rose subsp. bolaensis (Runge) Doweld. Arbusto suculento. Matorral xerófilo. Sierra La Paila y San Pedro de las Colonias, Coah.

* Thelocactus bicolor (Galeotti ex Pfeiff.) Britton \& Rose subsp. flavidispinus (Backeb.) N.P. Taylor. Arbusto suculento. Matorral xerófilo. Brewster Co., Tex.

* Thelocactus hexaedrophorus (Lem.) Britton \& Rose subsp. hexaedophorus. Arbusto suculento. Matorral xerófilo y pastizal. Dr. Arroyo, N.L.; cerca de Matehuala, Minas de San Rafael, La Ventura y El Huisache, S.L.P.; Tula, Tam.

* Thelocactus hexaedrophorus (Lem.) Britton \& Rose subsp. lloydii (Britton \& Rose) Kladiwa \& Fittkau. Arbusto suculento. Matorral xerófilo y pastizal. Fresnillo, Zac.

* Thelocactus lausseri Riha \& Busek. Arbusto suculento. Matorral xerófilo. Sierra Las Ovejas, Coah.

* Thelocactus macdowellii (Rebut ex Quehl) W.T. Marshall. Arbusto suculento. Matorral xerófilo. Coah.; N.L. (corredor SaltilloMonterrey).

* Thelocactus rinconensis (Poselger) Britton \& Rose subsp. nidulans (Quehl) Glass. Arbusto suculento. Matorral xerófilo. San Pedro y Saltillo, Coah.; entre Icamole-Monterrey, N.L.

* Thelocactus rinconensis (Poselger) Britton \& Rose subsp. phymatothele (Poselger ex Rumpler) Glass. Arbusto suculento. Matorral xerófilo. Ramos Arizpe y Saltillo, Coah.

* Thelocactus rinconensis (Poselger) Britton \& Rose. subsp. rinconensis. Arbusto suculento. Matorral xerófilo. Arteaga y Saltillo, Coah.; San Felipe y Villa de García, N.L. 
Apéndice: Continuación.

* Thelocactus tulensis (Poselger) Britton \& Rose. Arbusto suculento. Matorral xerófilo y submontano. N de S.L.P.; SO de Tam.

* Turbinicarpus beguinii (N.P. Taylor) Mosco \& Zanovello subsp. pailanus (Halda \& Panar.) U. Guzmán. Arbusto suculento. Matorral xerófilo. Sierra La Paila, Coah.

* Turbinicarpus gielsdorfianus (Werderm.) John \& Riha. Arbusto suculento. Matorral xerófilo. Las Tablas, S.L.P.

* Turbinicarpus laui Glass \& R.A. Foster. Arbusto suculento. Matorral halófilo y gipsófilo. Los Cerritos, S.L.P.

* Turbinicarpus lophophoroides (Werderm.) Buxb. \& Backeb. Arbusto suculento. Matorral halófilo y gipsófilo. Las Tablas, S.L.P.

* Turbinicarpus mandragora (Frič ex A. Berger) Zimmerman. Arbusto suculento. Matorral xerófilo. Sierra de Parras y Viesca, Coah.

* Turbinicarpus pseudopectinatus (Backeb.) Glass \& R.A. Foster. Arbusto suculento. Matorral xerófilo. Dr. Arroyo y Galeana, N.L.; Miquihuana, Tam.

* Turbinicarpus saueri (Boed.) John \& Riha subsp. knuthianus (Boed.) Lüthy. Arbusto suculento. Matorral xerófilo y pastizal. Guadalcázar, S.L.P.

* Turbinicarpus schmiedickeanus (Boed.) Buxb. \& Backeb. subsp. flaviflorus (G. Frank \& A.B. Lau) Glass \& R.A. Foster. Arbusto suculento. Matorral xerófilo. Santa Rita, S.L.P.

* Turbinicarpus schmiedickeanus (Boed.) Buxb. \& Backeb. subsp. klinkerianus (Backeb. \& W. Jacobsen) Glass \& R.A. Foster. Arbusto suculento. Matorral xerófilo. Huisache, S.L.P.

* Turbinicarpus schmiedickeanus (Boed.) Buxb. \& Backeb. subsp. macrochele (Werderm.) N.P. Taylor. Arbusto suculento. Matorral xerófilo. Dr. Arroyo, N.L.; Matehuala, S.L.P.

* Turbinicarpus schmiedickeanus (Boed.) Buxb. \& Backeb. subsp. schmiedickeanus. Arbusto suculento. Matorral xerófilo. Miquihuana, Tam.

* Turbinicarpus schmiedickeanus (Boed.) Buxb. \& Backeb. subsp. schwarzii (Shurly) N.P. Taylor. Arbusto suculento. Matorral xerófilo. Entre El Huisache y la Cd. de S.L.P.

* Turbinicarpus subterraneus (Backeb.) A.D. Zimmerman. Arbusto suculento. Matorral xerófilo. Dr. Arroyo, N.L.

* Turbinicarpus valdezianus (Møller) Glass \& R.A. Foster. Arbusto suculento. Matorral xerófilo. Saltillo, Coah., Matehuala, S.L.P.; cerca de Cedros, Zac.

* Turbinicarpus viereckii (Werderm.) John \& Riha subsp. major (Glass $\&$ R.A. Foster) Glass. Arbusto suculento. Matorral xerófilo. Cerca de Mier y Noriega, N.L.; Presa de Guadalupe y Lázaro Cárdenas, S.L.P.

\section{Campanulaceae (2000/13/2)}

$*(* * *)$ Lobelia anatina E. Wimm. var. riskindii M.C. Johnst. Hierba perenne. Bosque de coníferas. Sierra El Carmen, Coah.
*(***) Lobelia henricksonii M.C. Johnst. Hierba perenne. Matorral submontano. Sierras La Gavia y La Paila, Coah.

Capparaceae (600/8/1)

* Cleomella longipes Torr. Hierba anual. Matorral xerófilo. Montañas de Chiricahua, Ariz., Valle San Pablo, Chih.; Montañas de Chisos, Tex.

Caprifoliaceae (500/10/2)

*(***) Abelia coriacea Hemsl. var. coriacea. Arbusto. Bosque de pino-encino. Sierra San Miguel, S.L.P.

**(***) Abelia coriacea Hemsl var. subcoriacea Villarreal. Arbusto. Matorral submontano. Sierras La Alcaparra y de Carrasco, Chih.; Sierras de Coah.; Galeana, Guadalupe, San Pedro Garza García, Santiago y Villaldama, N.L.

Caryophyllaceae (1750/44/16)

* Arenaria hintoniorum B.L. Turner. Hierba perenne. Matorral halófilo y gipsófilo. San Roberto, Galeana, N.L.

* Arenaria livermorensis Correll. Hierba perenne. Matorral xerófilo. Montañas de Davis, Tex.

* Arenaria ludens Shinners. Hierba anual. Bosque de pino-encino. Sierras El Carmen y Santa Rosa, Coah.; Trans-Pecos, Tex.

* Drymaria axillaris Brandegee. Hierba perenne. Matorral halófilo y gipsófilo. Sierra La Paila y Laguna del Rey, Coah.

** Drymaria barkleyi Steyerm. \& J.A. Duke. Hierba perenne. Matorral xerófilo. Límites entre Coah. y N.L.

* Drymaria elata I.M. Johnst. Hierba perenne. Matorral halófilo y gipsófilo. Laguna del Rey, Coah.

* Drymaria jenniferae Villarreal \& Estrada. Hierba perenne. Matorral halófilo y gipsófilo. Viesca, Coah.

* Drymaria lyropetala I.M. Johnst. var. coahuilana I.M. Johnst. Hierba perenne. Matorral halófilo y gipsófilo. Aldama, Chih.; C de Coah.; O y C de N.L.

* Drymaria lyropetala I.M. Johnst. var. lyropetala. Hierba perenne. Matorral halófilo y gipsófilo. C de Chih.; SO de N.L.; N de S.L.P.

** Drymaria pachyphylla Woot. \& Standl. Hierba anual. Vegetación riparia. SE de Ariz., Sierra Hechiceros, Chih.; Laguna La Leche y Monclova, Coah., Sierra Santa Rita, Dgo.; Mina, N.L.; Doña Ana Co., N.M.; Trans-Pecos, Tex.

* Drymaria polycarpoides A. Gray. Hierba perenne. Matorral halófilo y gipsófilo. Bolsón de Mapimi, Chih.; Cuatro Ciénegas y Viesca, Coah.; Bolsón de Mapimí, Dgo.; Mazapil, Zac.

* Drymaria pratheri B.L. Turner. Hierba perenne. Matorral gipsófilo. NO de N.L.

* Drymaria subumbellata I.M. Johnst. Hierba perenne. Matorral xerófilo. Sierra La Paila y Laguna del Rey, Coah.

* Drymaria suffruticosa A. Gray ex. S. Watson. Hierba perenne. Matorral xerófilo. San Lorenzo de Laguna, Coah. 
Apéndice: Continuación.

* Paronychia albomarginata Core. Hierba perenne. Matorral xerófilo. Coah.; N.L. (corredor Saltillo-Monterrey).

* Paronychia wilkinsonii S. Watson. Hierba perenne. Matorral xerófilo. Sierra Hechiceros, Chih.; Sierra Hechiceros y del Pino, Coah.; Brewster Co., Tex.

Celastraceae (500/10/2)

* Canotia wendtii M.C. Johnst. Arbusto. Matorral xerófilo. Rancho Boquillas, Chih.

*(***) Mortonia latisepala I.M. Johnst. Arbusto. Matorral submontano. Cerca de Torreón y Sierra La Gavia, Coah.

Chenopodiaceae (1500/52/10)

* Atriplex abata I.M. Johnst. Hierba perenne. Matorral halófilo y gipsófilo. La Ventura, Coah.; Sierra San Miguel, S.L.P.

* Atriplex acanthocarpa (Torr.) S. Watson. subsp. coahuilensis Henrickson. Hierba perenne. Matorral halófilo y gipsófilo. Cuatro Ciénegas, Viesca y Saltillo, Coah.; Río Grande, Tex.; Concepción del Oro, Zac.

* Atriplex acanthocarpa (Torr.) S. Watson subsp. stewartii (I.M. Johnst.) Henrickson. Hierba perenne. Matorral halófilo y gipsófilo. Bolsón de Mapimí, Chih.; Sierra Las Delicias, Cuatro Ciénegas, Lagunas del Rey y del Guaje, Coah.

* Atriplex prosopidium I.M. Johnst. Arbusto. Matorral halófilo y gipsófilo. Cuatro Ciénegas, Monclova y Laguna del Rey, Coah.

** Atriplex reptans I.M. Johnst. Hierba perenne. Matorral halófilo y gipsófilo. Laguna del Jaco, Coah.; Galeana y San Roberto, N.L.

* Atriplex monilifera S. Watson. Hierba anual. Matorral halófilo y gipsófilo. Laguna de Mayran y Viesca, Coah.

** Dysphania stellata (S.Watson) Mosyakin \& Clemants. Hierba anual. Matorral halófilo y gipsófilo. Cuatro Ciénegas, Monclova, Lagunas del Jaco y del Rey, Coah.

** Suaeda jacoensis I.M. Johnst. Hierba perenne. Matorral halófilo y gipsófilo. Laguna de Jaco, O y C de Coah.; SO de N.L.; Lagunilla de Salinas, C de S.L.P.

** Suaeda llanoensis Henrickson. Hierba perenne. Matorral halófilo y gipsófilo. San Roberto, San José de Raices, N.L.; Lagunilla de Salinas, C de S.L.P.

* Suaeda palmeri (Standl.) Standl. Arbusto. Matorral halófilo y gipsófilo. Sierra de Parras, Cuatro Ciénegas, Monclova, Laguna de Mayrán y Viesca, Coah.; Galeana, N.L.; Concepción del Oro, Zac.

Cistaceae (200/3/1)

*(***) Lechea mensalis Hodgdon. Hierba perenne. Bosque de pino-encino. Sierra El Carmen, Coah.; Montañas de Chisos y Brewster Co., Tex. Convolvulaceae (1500/38/4)

* Bonamia multicaulis (Brandegee) House. Subarbusto. Matorral xerófilo. Bolsón de Mapimí, Chih.; Bolsón de Mapimí y Laguna del Rey, Coah.; Sierra El Rosario y Cuencamé, Dgo.
* Bonamia ovalifolia (Torr.) Hallier f. Hierba perenne. Vegetación riparia. Río Grande, Tex.

* Ipomoea zimmermanii J.A. McDonald. Hierba perenne. Matorral xerófilo y submontano. Sierra La Paila, Coah.

* Petrogenia repens I.M. Johnst. Hierba perenne. Matorral xerófilo. Sierras Santa Eulalia y San Carlos, Chih.; Sierras Las Cruces y Hechiceros, Coah.; Minas de San Rafael, S.L.P.; Trans-Pecos, Tex.

Crassulaceae (1500/32/3)

* Echeveria turgida Rose. Hierba perenne. Matorral xerófilo. Sierra Las Delicias y Viesca, Coah.

*(***) Lenophyllum weinbergii Britton. Hierba perenne. Matorral submontano. Sierra La Paila, Coah.

* Sedum parvum Hemsl. subsp. dendroides R.T. Clausen. Subarbusto. Matorral xerófilo. Sierra Catorce, S.L.P.

Cuscutaceae (170/15/1)

* Cuscuta decipiens Yunck. Parásita. Matorral xerófilo. Brewster Co., Tex.; Hacienda de Cedros, Zac.

Ericaceae (3000/6/1)

*(***) Comarostaphylis polifolia (Kunth) Zucc. ex Klotzsch subsp. coahuilensis Henrickson. Arbusto. Matorral submontano y bosque de pino-encino. Sierra Almagre, Chih.; Sierras La Paila, La Madera y de Parras, Coah.

Euphorbiaceae (7000/102/21)

* Cnidoscolus shrevei I.M. Johnst. Arbusto. Matorral xerófilo. Sierra Jimulco, Coah.; Sierra El Rosario, Dgo.

** Croton sancti-lazari Croizat. Arbusto. Matorral xerófilo. Sierra del Diablo, Chih.; Sierras Almagre, La Gavia, Jimulco y Castaños, Coah.; Sierra El Rosario, Dgo.; Big Bend, Tex.

* Euphorbia correllii M.C. Johnst. Hierba perenne. Matorral gipsófilo. Entronque a Galeana, N.L.

* Euphorbia crepitata L.C. Wheeler var. crepitata. Hierba perenne. Matorral halófilo y gipsófilo. Cuatro Ciénegas, Coah.

* Euphorbia crepitata L.C. Wheeler var. longa M.C. Johnst. Hierba perenne. Matorral halófilo y gipsófilo. Cerca del Puerto Ventanillas, Coah.

* Euphorbia cressoides M.C. Johnst. Hierba perenne. Bosque de pino piñonero. Sierra Jimulco, Coah.

**(***) Euphorbia exstipulata Engelm. Hierba anual. Matorral submontano. Laguna Las Palomas, Chih.; SO de California, Cuencamé, Dgo.; Brewster y Presidio Cos., Tex.

* Euphorbia fruticulosa Engelm. ex Boiss. var. fruticulosa. Hierba perenne. Matorral halófilo y gipsófilo. Cuatro Ciénegas y SO de la cuenca Las Delicias, Coah.; Río Nazas, Dgo.; Galeana, N.L.

* Euphorbia fruticulosa Engelm. ex Boiss. var. hirtella M.C. Johnst. Hierba perenne. Matorral halófilo y gipsófilo. E del Coyote, Coah. 
Apéndice: Continuación.

**(***) Euphorbia furcillata Kunth var. ribana M.C. Johnst. Hierba perenne. Matorral submontano. Cerca de Saltillo, Coah.; cerca del Rancho Zaragoza, N.L.; Sierra El Astillero; Concepción del Oro, Zac.

* Euphorbia henricksonii M.C. Johnst. Hierba anual. Matorral xerófilo. Bajío El Gringo, Chih.

*(***) Euphorbia ivanjohnstonii M.C. Johnst. Hierba perenne. Matorral submontano. Sierra del Pino, Coah.

* Euphorbia neilmuellerii M.C. Johnst. Hierba perenne. Matorral gipsófilo. San Roberto y S de N.L.

* Euphorbia perennans (Shinners) Warnock \& M.C. Johnst. Hierba perenne. Matorral xerófilo. Mesa de Anguila al S del Rio Grande, Chih.; Brewster y Presidio Cos., Tex.

*(***) Euphorbia pinkavana M.C. Johnst. Hierba perenne. Bosque de pino piñonero. Sierra La Madera, Coah.

* Euphorbia theriaca L.C. Wheeler var. spurca M.C. Johnst. Hierba anual. Matorral xerófilo. Laguna Las Palomas y Guadalupe Victoria, Chih.; Bolsón de Lipanes, Coah.; Big Bend, Tex.

* Euphorbia theriaca L.C. Wheeler var. theriaca. Hierba anual. Matorral xerófilo. Río Grande, Coah.; Presidio Co., Tex.

* Euphorbia simulans (L.C. Wheeler) Warnock \& M.C. Johnst. Hierba perenne. Matorral xerófilo. Sierra Santa Elena, Chih.; Montañas de Chisos, Big Bend, Brewster y Presidio Cos., Tex.

* Phyllanthopsis arida (Warnock \& M.C. Johnst.) Voronts. \& Petra Hoffm. Arbusto. Matorral xerófilo. Sierra del Roque, Chih.; Picacho de San José, Coah.; Brewster y Presidio Cos., Tex.

* Phyllanthus ericoides Torr. Hierba perenne. Vegetación riparia. Río Grande, Chih.; Brewster Co., Tex.

*(***) Phyllanthus fraguensis M.C. Johnst. Arbusto. Bosque de pino piñonero. Sierra La Fragua, Coah.

Fabaceae (18000/286/28)

* Acacia angustissima (Mill.) Kuntze var. chisosiana Isely. Arbusto. Matorral xerófilo. Sierras del Diablo y Hechiceros, Chih.; Sierra Carneros, Coah.; Bolsón de Mapimí, Dgo.; Trans-Pecos, Tex.

* Acacia glandulifera S. Watson. Arbusto. Matorral xerófilo y bosque de pino piñonero. Sierra del Diablo y Coyame, Chih.; Sierras del Pino, de Parras, Carneros y Jimulco, Coah.; Sierra El Rosario, Dgo.; San Rafael, N.L.; Concepción del Oro, Zac.

* Acacia schottii Torr. Arbusto. Matorral xerófilo. Brewster Co., Tex. *(***) Astragalus carminis Barneby. Hierba perenne. Bosque de pinoencino. Sierra Almagre, Chih.; Sierras La Madera, La Encantada, El Carmen, del Pino y Santa Rosa, Coah.

* Astragalus emoryanus (Rydb.) Cory. var. terlinguensis (Cory) Barneby. Hierba perenne. Matorral xerófilo. Ocampo, Coah., TransPecos, Tex.

* Astragalus mollissimus Torr. var. marcidus (Rydb.) B.L. Turner. Hierba perenne. Matorral xerófilo. Montañas de Chinati y Davis, Tex.
* Astragalus pomphocalyx Villarreal \& Carranza. Hierba perenne. Matorral xerófilo. Ramos Arizpe, Coah.

*(***) Astragalus rupertii Villarreal \& Carranza. Hierba perenne. Matorral submontano. Estación Vega Saltillo, Coah.

** Brongniartia minutifolia S. Watson. Arbusto. Matorral xerófilo. Mata Ortiz y Rosales, Chih.; Montañas de Chisos, Big Bend y Brewster Co., Tex.

* Caesalpinia parryi (Fisher) Eifert. Arbusto. Matorral xerófilo. Sierra Jimulco y Saltillo, Coah.; Brewster, Pecos y Presidio Cos., Tex.; Sierra del Yeso, Zac.

* Coursetia insomniifolia Lavin. Arbusto. Matorral xerófilo. Puerto Ventanillas, Coah.

*(***) Dalea bartonii Barneby. Hierba perenne. Bosque de pino piñonero. San Francisco Creek y Brewster Co., Tex.

** Dalea capitata S. Watson. Arbusto. Matorral xerófilo. Sierra de Parras, Ramos Arizpe y Saltillo, Coah.; Cuencamé, Dgo.; Rancho El Aguililla y San Roberto, N.L.; Matehuala, S.L.P.; N de Zac.

* Dalea eriophylla S. Watson. var. frankenioides Barneby. Arbusto. Matorral xerófilo. Sierra Catorce, S.L.P.

* Dalea janosensis A.E. Estrada \& Villarreal. Hierba perenne. Matorral xerófilo, bosque de pino-encino y pastizal. Janos y Rancho Las Arenillas, Chih.

* Dalea melantha S. Schauer var. pubens Barneby. Hierba perenne. Matorral xerófilo. Sierra Jimulco, Coah.

* Dalea neo-mexicana (A. Gray) Cory. var. megaladenia Barneby. Hierba perenne. Matorral xerófilo. Cerca de Cd. de Chih.; Sierras Santa Rosa y El Carmen, Coah.; Cuencamé, Dgo.; Big Bend, Tex.

* Dermatophyllum purpusii (Brandegee) Vincent. Arbusto. Matorral xerófilo. Sierra de Parras, Coah.

* Eysenhardtia parvifolia Brandegee. Arbusto. Matorral xerófilo. Sierras La Paila y de Parras, Coah.; El Huisache, Cerro Calvo y Guadalcázar, S.L.P.; Miquihuana, Tam.

** Genistidium dumosum I.M. Johnst. Arbusto. Matorral xerófilo. Sierras Los Alamos, Las Cruces y Rancho Puerto Colorado, Coah.; Aramberri, N.L.; Brewster Co., Tex.

* Mimosa setuliseta Villarreal. Arbusto. Matorral xerófilo. Cerro San Ignacio y Sierra El Rosario, Dgo.; Paso del Aguila, S.L.P.; Tula, Tam.

**(***) Nissolia platycalyx S. Watson. Hierba perenne. Matorral submontano. Sierra de Parras, Cuatro Ciénegas, Arteaga, Múzquiz, Ramos Arizpe y Torreón, Coah.; Galeana, N.L., Montañas de Chisos, Tex.; Concepción del Oro, Zac.

**(***) Phaseolus plagiocylix Harms. Hierba perenne. Matorral submontano. Sierra La Paila, Coah.; Cerro del Obispado, N.L.

* Pomaria fruticosa (S. Watson) B.B. Simpson. Arbusto. Matorral xerófilo. Sierras Las Delicias y Jimulco, Coah.; Sierra El Rosario, Dgo. 
Apéndice: Continuación.

* Senna monozyx (H.S. Irwin \& Barneby) H.S. Irwin \& Barneby. Arbusto. Matorral xerófilo. Sierras La Madera, La Paila y Mojada, Coah.

* Senna pilosior (B.L. Rob ex J.F. Macbr.) H.S. Irwin \& Barneby. Hierba anual. Matorral xerófilo. Bolsón de Mapimí, Chih.; Sierra de Parras, Coah., Bolsón de Mapimí, Dgo.; Big Bend, Tex.

* Senna ripleyana (H.S. Irwin \& Barneby) H.S. Irwin \& Barneby. Hierba perenne. Matorral xerófilo y pastizal. Bolsón de Mapimí, Jiménez y Rancho La Gloria, Chih.; Brewster y Trans-Pecos Co., Tex.; Cedros, Zac.

* Sophora arizonica S. Watson var. gypsophila B.L. (Turner \& A.M. Powell) Henrickson. Arbusto. Matorral halófilo y gipsófilo. Coyame y Ojinaga, Chih.; Montañas de Guadalupe y Culberson Co., Tex.

Fagaceae (900/40/10)

*(***) Quercus carmenensis C.H. Mull. Arbusto. Bosque de encino. Sierra El Carmen, Coah.; Brewster Co., Tex.

*(***) Quercus coahuilensis Nixon \& C.H. Mull. Arbusto. Matorral submontano. Sierra del Diablo, Chih.; Sierras La Concordia, La Madera, del Pino y Jimulco, Coah.

* Quercus deliquescens C.H. Mull. Arbusto. Matorral xerófilo y submontano. Valle del Río Concho y Río Grande, Chih.

**(***) Quercus gravesii Sudw. Árbol. Bosque de encino. Sierras La Gavia, La Paila, El Carmen y La Madera, Coah.; Trans-Pecos, Tex.

*(***) Quercus hinckleyi C.H. Mull. Arbusto. Matorral submontano. Shafter y Presidio Co., Tex.

**(***) Quercus invaginata Trel. Arbusto a árbol. Matorral submontano y bosque de encino. Sierras LaGavia, La Gloria, La Paila y Pájaros Azules, Coah.; Aramberri y Galeana, N.L.

*(***) Quercus pungens Liebm. var. pungens. Árbol. Matorral submontano. Sierras del Diablo, Santa Eulalia, Rancho Madera y Almagre, Chih.; Sierra Mojada, Coah.; Montañas de Franklin, Tex. *(***) Quercus robusta C.H. Mull. Árbol. Bosque de pino-encino. Montañas de Chisos, Tex.

*(***) Quercus saltillensis Trel. Árbol. Bosque de encino. Sierras La Concordia, La Paila, de Parras y Zapalinamé, Coah.; Galeana, N.L.

*(***) Quercus tinkhamii C.H. Mull. Arbusto. Matorral submontano.

Dr. Arroyo, N.L.; La Joya al NE de Ventura, S.L.P.

Fouquieriaceae (11/2/1)

* Fouquieria shrevei I.M. Johnst. Arbusto. Matorral halófilo y gipsófilo. Bolsón de Mapimí y Cuatro Ciénegas, Coah.

Gentianaceae (1000/10/3)

* Eustoma barkleyi Standl. ex Shinner. Hierba perenne. Vegetación riparia. Ojo Caliente, Coah.; Mina, N.L.

* Sabatia tuberculata J.E. Williams. Hierba anual. Matorral halófilo y gipsófilo. Cuatro Ciénegas, Coah.
** Zeltnera maryanniana (B.L. Turner) G. Mans. Hierba anual. Matorral halófilo y gipsófilo. Chaves y Eddy Co., N.M.; Culberson Co., Tex.

Lamiaceae (3500/97/25)

*(***) Agastache cana (Hook.) Wooton \& Standl. Hierba perenne. Matorral submontano. HuecoTanks, Montañas de Franklin y Río Grande, Tex.

*(***) Clinopodium maderense (Henrickson) Govaerts. Hierba perenne. Bosque de coníferas. Sierra La Madera, Coah.

$*(* * *)$ Hedeoma chihuahuensis (Henrickson) B.L. Turner. Hierba perenne. Matorral submontano. Sierra Hechiceros, Chih.; Sierra Hechiceros, Coah.

*(***) Hedeoma irvingii B.L. Turner. Arbusto. Matorral submontano. Saltillo, Coah.

$*(* * *)$ Hedeoma johnstonii R.S. Irving. Hierba perenne. Matorral submontano y bosque de encino. Sierra El Carmen, Coah.

*(***) Hedeoma mollis Torr. Hierba perenne. Matorral submontano. Montañas de Chinati, Davis y Tierra Vieja, Tex.

*(***) Hedeoma montana Brandegee. Arbusto. Matorral submontano. Sierras La Paila, La Fragua, Los Órganos y Remedios, Coah.

*(***) Hedeoma patrina W.S. Stewart. Hierba perenne. Matorral submontano y bosque de pino piñonero. Sierra del Diablo, Chih.; Sierras Mojada, Las Cruces, La Madera, de Parras, Coah.; Concepción del Oro, Zac.

*(***) Hedeoma pilosa R.S. Irving. Hierba perenne. Matorral submontano y bosque de pino-encino. Montañas de Baldy Peak, Vidrio y Brewster Co., Tex.

**(***) Poliomintha dendritica B.L. Turner. Arbusto. Matorral submontano. Sierra San Marcos, Coah.; Sierra Lampazos, N.L.

*(***) Poliomintha maderensis Henrickson. Arbusto. Bosque de coníferas. Sierra La Madera, Coah.

** Salvia chionophylla Fernald. Hierba perenne. Matorral halófilo y gipsófilo. SO de Saltillo, Coah.

* Salvia coahuilensis Fernald. Hierba perenne. Matorral xerófilo. Sierras LaGavia, de Parras y San Marcos, Coah.; Galeana, N.L.

* Salvia jessicae B.L. Turner. Arbusto. Matorral halófilo y gipsófilo. N de San Pedro de las Colonias, Coah.

*(***) Salvia lanicalyx Epling. Hierba perenne. Matorral submontano. Sierra de Parras, Coah.

** Salvia lycioides A. Gray. Arbusto. Matorrales xerófilo, halófilo, gipsófilo y submontano. Chih.; Coah.; Dgo.; N.L.; N.M.; S.L.P.; Tex.

*(***) Salvia monclovensis Fernald. Hierba perenne. Bosque de pinoencino. Sierras La Madera, La Gavia y La Gloria, Coah.

*(***) Salvia pennellii Epling. Hierba perenne. Matorral submontano y bosque de encino. Sierra Catorce, S.L.P. 
Apéndice: Continuación.

*(***) Salvia pseudopallida Epling. Hierba perenne. Bosque de coníferas. Sierra La Madera, Coah.

*(***) Salvia purpusii Brandegee. Arbusto. Matorral submontano. Sierra Zapatero, Coah.

*(***) Salvia vinacea Woot. \& Standl. Arbusto. Matorral submontano.

Sierra Bismarck, Chih., Montañas de Florida, N.M.; Montañas de Franklin, Tex.

*(***) Scutellaria carmenensis Henrickson. Hierba perenne. Bosque de pino-encino. Sierra El Carmen, Coah.

*(***) Scutellaria laevis Shinners. Hierba perenne. Matorral submontano y bosque de pino-encino. Sierra del Diablo, Chih.; Cañon Victorio y Trans-Pecos, Tex.

*(***) Scutellaria wendtii Henrickson. Arbusto. Matorral submontano. Sierra El Morrión, Chih.

* Trichostema mexicanum Epling. Subarbusto. Matorral xerófilo. Sierra La Gavia, Coah.; Guadalcázar, S.L.P.; Concepción del Oro, Zac.

Linaceae (220/13/3)

* Linum allredii Sivinski \& M.O. Howard. Hierba perenne. Matorral halófilo y gipsófilo. Eddy Co., N.M.; Montañas de Guadalupe, Río Pecos y Culberson Co., Tex.

** Linum flagellare (Small) H.J.P. Winkl. Hierba perenne. Matorral xerófilo. Sierras Las Delicias y de Parras, Coah.; La Zarca, Dgo.; Hacienda de Cedros, Zac.

* Linum vernale Wooton. Hierba anual. Matorral xerófilo. Sierra del Diablo, Chih.; Sierra del Pino, Coah.; y Trans-Pecos, Tex.

Loasaceae (200/22/5)

*(***) Eucnide durangensis H.J. Thomps. \& A.M. Powell. Hierba perenne. Matorral submontano. Sierra Jimulco, Coah.; Sierra El Rosario, Dgo.

*(***) Eucnide xylinea C.H. Mull. Hierba perenne. Matorral submontano y bosque de pino. Sierras Mojada y La Madera, Coah.; Miquihuana, Tam.

* Mentzelia humilis (Urb. \& Gilg) J. Darl. var. guadalupensis Spellenb. Hierba perenne. Matorral gipsófilo. Otero Co., N.M.

* Mentzelia saxicola H.J. Thomps. \& Zavort. Hierba perenne. Matorral xerófilo. Camino al Rancho San José del Progreso, Chih.; Sierra de Parras y General Cépeda, Coah.; El Paso, Tex.

* Petalonyx crenatus A. Gray ex S. Watson. Arbusto. Matorral halófilo y gipsófilo. Cuatro Ciénegas, Coah.

Lythraceae (575/7/1)

* Nesaea longipes A. Gray. Hierba perenne. Vegetación riparia. Cerca de Múzquiz y Monclova, Coah.; cerca de las Montañas de Chisos, Río Grande, Zacate Creek y Kinney Cos., Tex.

\section{Malpighiaceae (1000/8/1)}

* Echinopterys setosa Brandegee. Arbusto. Matorral xerófilo y submontano. Sierras La Madera y La Paila, Coah.

\section{Malvaceae (1000/57/7)}

* Abutilon coahuilae Kearney. Subarbusto. Matorral xerófilo. Sierras La Paila, de Parras y Cuatro Ciénegas, Coah.

* Allowissadula chiangii M.C. Johnst. Subarbusto. Matorral xerófilo. Sierra Los Órganos, Chih.; cerca del Cubo, S.L.P.

*(***) Batesimalva lobata Villarreal \& Fryxell. Hierba perenne. Matorral submontano. Sierra Jimulco, Coah.; Sierra El Rosario, Dgo.

** Fryxellia pygmaea (Correll) Bates. Hierba perenne. Matorral xerófilo. C y E de Coah.; S de Tex.

** Sida longipes A. Gray. Hierba perenne. Matorral halófilo y gipsófilo. Cuatro Ciénegas, Coah.; Winkler Co., Tex.

* Sphaeralcea endlichii Ulbr. Subarbusto. Matorral xerófilo. Sierra del Diablo, Chih.; Sierras La Paila, de Parras y Viesca, Coah.; Cuencamé, Dgo.; Mina, N.L.; Concepción del Oro, Zac.

* Sphaeralcea reflexa Fryxell, Valdés-Reyna \& Villarreal. Hierba perenne. Matorral xerófilo. Sierra Jimulco, Coah.; Sierra El Rosario, Dgo.

\section{Martyniaceae (20/5/1)}

* Proboscidea spicata Correll. Hierba anual. Matorral xerófilo. Sierra El Carmen, Coah.; Trans-Pecos, Tex.

\section{Nyctaginaceae (290/52/11)}

** Acleisanthes chenopodioides (A. Gray) R.A. Levin. Hierba perenne. Matorral xerófilo. SE Ariz.; S y C de Chih.; O de Tex.

* Acleisanthes palmeri (Hemsl.) R.A. Levin. Arbusto. Matorral halófilo y gipsófilo. Sierra Solis, Laguna de Mayrán y Torreón, Coah.

* Acleisanthes parvifolia (Torr.) R.A. Levin. Subarbusto. Matorral xerófilo. Sierra Santa Elena, Chih.; Brewster y Presidio Cos., Tex.

** Acleisanthes purpusiana (Heimerl) R.A. Levin var. purpusiana. Arbusto. Matorral gipsófilo. Laguna del Rey, Cuatro Ciénegas, E y $\mathrm{C}$ de Coah.

** Acleisanthes wrightii (A. Gray) Benth. \& Hook. f. ex Hemsl. Hierba perenne. Pastizal. Val Verde y Reeves Cos., Tex.

* Anulocaulis eriosolenus (A. Gray) Standl. Hierba perenne. Matorral xerófilo y gipsófilo. Big Bend, Tex.; $\mathrm{N}$ y $\mathrm{C}$ de Coah.

* Anulocaulis leiosolenus (Torr.) Standl. var. gypsogenus (Waterf.) Spellenb. \& T. Wootten Hierba perenne. Matorral gipsófilo. Chaves Co., N.M.; Culberson y Reeves Cos., Tex.

** Anulocaulis leiosolenus (Torr.) Standl. var. howardii Spellenb. \& T. Wootten. Hierba perenne. Matorral gipsófilo. Guadalupe Mountains, $\mathrm{S}$ y $\mathrm{C}$ de N.M.

* Anulocaulis leiosolenus (Torr.) Standl. var. lasianthus I.M. Johnst. Hierba perenne. Matorral xerófilo. N de Chih.; Brewster y Presidio Cos., Tex.

* Anulocaulis hintoniorum B.L. Turner. Hierba perenne. Matorral xerófilo, halófilo y gipsófilo. Sierra de Parras, Coah. 
Apéndice: Continuación.

* Anulocaulis reflexus I.M. Johnst. Hierba perenne. Matorral halófilo y gipsófilo. NE de Jumiles, Chih.; Presidio y Jeff Davis Cos., Tex. Oleaceae $(600 / 20 / 1)$

* Menodora hintoniorum B.L. Turner. Hierba perenne. Matorral xerófilo, halófilo y gipsófilo. Valle de Navidad, Galeana, N.L.

Onagraceae (650/46/1)

* Gaura macrocarpa Rothr. Hierba perenne. Vegetación riparia. Cerro del Gallego, Chih.; Brewster, Jeff Davis y Presidio Cos., Tex.

Orobanchaceae $(2200 / 20 / 5)$

** Aureolaria greggii (S. Watson) Pennell. Subarbusto. Matorral xerófilo. S de Coah.; Sierra El Rosario y Cuencamé, Dgo.; Aramberri, Dr. Arroyo y Galeana, N.L.; Guadalcázar, S.L.P.; Concepción del Oro y Mazapil, Zac.

*(***) Castilleja wootonii Standl. Hierba perenne. Bosque de pinoencino. Montañas de Davis, Tex.

*(***) Seymeria coahuilana (Pennell) Standl. Hierba anual. Matorral submontano. Sierra La Gloria, Coah.

*(***) Seymeria falcata B.L. Turner var. falcata. Hierba anual. Matorral submontano. Sierras La Fragua, El Carmen y del Pino, Coah.

*(***) Seymeria falcata B.L. Turner var. uncinata B.L. Turner. Hierba anual. Matorral submontano. Sierras del Diablo y Chupaderos, Chih.; Sierras La Madera y Mojada, Coah.

*(***) Seymeria pailana B.L. Turner. Hierba anual. Matorral submontano y bosque de encino. Sierras La Paila y La Gavia, Coah.

Papaveraceae $(250 / 15 / 4)$

** Argemone brevicornuta G.B. Ownbey. Hierba perenne. Matorral xerófilo. Cerca de Meoquí, Chih.

** Argemone chisosensis G.B. Ownbey. Hierba perenne. Matorral xerófilo. Bolsón de Mapimí, Chih.; Sierras Mojada, Las Cruces, Cuatro Ciénegas, Arteaga y Múzquiz, Coah.; Cuencamé, Dgo.; Trans-Pecos, Tex.

* Argemone fruticosa Thurber ex A. Gray. Hierba perenne. Matorral xerófilo. Sierras de Parras, El Venado y Torreón, Coah.

* Argemone turnerae A.M. Powell var. ownbeyana (M.C. Johnst.) Schwarzbach. Hierba perenne. Matorral halófilo y gipsófilo. Ojinaga, Chih.

* Argemone turnerae A.M. Powell. var. turnerae. Hierba perenne. Vegetación riparia. Cerca de la Presa del Granero, O del Río Conchos, Chih.

Plantaginaceae (1000/24/6)

* Mabrya coccinea (I.M. Johnst.) Elisens. Hierba perenne. Matorral xerófilo. Sierra Las Delicias, Coah.

* Mabrya erecta (Hemsl.) Elisens. Hierba perenne. Matorral halófilo, gipsófilo y submontano. Sierra del Diablo, Chih.; Sierras Solis, La
Madera, Las Delicias, de Parras y Viesca, Coah.; Sierra Misericordia, Cerro La Bufa y San Ignacio, Dgo.; Mina, N.L.

* Maurandya antirrhiniflora Humb. \& Bonpl. ex Willd. subsp. hederifolia. (Rothm.) Elisens. Hierba perenne. Matorral halófilo y gipsófilo. Sierra de Parras, General Cepeda y Ramos Arizpe, Coah.; Dr. Arroyo, Galeana y Mina, N.L.

*(***) Penstemon henricksonii Straw. Hierba perenne. Bosque de pino-encino. Sierra La Madera, Coah.

*(***) Penstemon punctatus Brandegee. Arbusto. Matorral submontano y bosque de pino-encino. Sierra La Paila, Coah.

* Stemodia coahuilensis (Henrickson) B.L. Turner. Hierba anual. Matorral xerófilo. Sierra del Diablo, Chih.; Coah.; Sierra El Rosario, Dgo.; Concepción del Oro, Zac.

Polemoniaceae $(300 / 30 / 2)$

* Giliastrum purpusii (Brandegee) J.M. Porter. Hierba perenne. Matorral xerófilo. Matamoros y Viesca, Coah.

*(***) Ipomopsis wendtii Henrickson. Hierba perenne. Bosque de pino-encino. Sierra El Carmen, Coah.

Polygalaceae (800/24/7)

* Polygala maravillasensis Correll. Hierba perenne. Matorral xerófilo. Sierra Hechiceros, Chih.; Sierras El Carmen y Santa Rosa, Cañón del Río Bravo, Coah.; Maravillas Creek y Brewster Co., Tex.

* Polygala nudata Brandegee. Hierba perenne. Matorral xerófilo y submontano y bosque de pino piñonero. Sierra del Diablo, Chih.; Sierra La Paila y Torreón, Coah.; Galeana, N.L.; S de TransPecos, Tex.

*(***) Polygala parrasana Brandegee. Hierba perenne. Matorral submontano. Sierras La Paila, de Parras, Jimulco y Mojada, Coah.

*(***) Polygala rimulicola Steyerm. var. mescalerorum T. Wendt \& Todsen. Hierba perenne. Matorral submontano. Montañas de San Andres y Doña Ana Co., N.M.

** Polygala semialata S. Watson. Hierba perenne. Matorral xerófilo, submontano y pastizal. Sierra Hechiceros, Chih.; Cuatro Ciénegas, Coah.; Sierra El Rosario y Cuencamé, Dgo.; Monterrey, N.L.; Las Charcas, S.L.P.; Concepción del Oro, Zac.

*(***) Polygala viridis S. Watson. Hierba perenne. Matorral submontano y bosque de encino. Sierras La Gloria y del Pino, Coah.

** Polygala watsonii Chodat. Hierba perenne. Matorral xerófilo y submontano. Sierra Santa Eulalia, Chih.; Cuatro Ciénegas y Ramos Arizpe, Coah.; Sierra El Rosario, Dgo.; Aramberri, Dr. Arroyo y Santa Rosa, N.L.; Sierra Catorce, S.L.P.; Miquihuana, Tam.; Montañas de Vidrio, Tex.; Concepción del Oro, Zac. 
Apéndice: Continuación.

\section{Polygonaceae $(800 / 40 / 14)$}

** Eriogonum abertianum Torr. var. cyclosepalum (Greene) Fosberg. Hierba anual. Matorral xerófilo, bosques de coníferas y encino y pastizal. Ariz.; Chih.; Coah.; N.M.; S.L.P.; Tex.

$*(* * *)$ Eriogonum atrorubens Engelm. var. rupestre (S. Stokes) W.J. Hess \& Reveal. Hierba perenne. Bosque de pino-encino y pastizal. Sierra Santa Elena, Chih.

** Eriogonum ciliatum Torr. ex. Benth. Hierba perenne. Matorral xerófilo, bosques de pino-encino, pino piñonero y juníperos. Buena Vista y Saltillo, Coah.; La Ascensión, N.L., Charcas, S.L.P.; SE de Bustamante, Tam.

* Eriogonum clivosum W.J. Hess \& Reveal. Hierba perenne. Matorral xerófilo, halófilo y gipsófilo. Cerca de Salinas del Peñón, S.L.P.; O del Tecomate, Zac.

* Eriogonum fimbriatum W.J. Hess \& Reveal. Hierba perenne. Matorral halófilo y gipsófilo. San Roberto, N.L.

* Eriogonum gypsophilum Wooton \& Standl. Hierba perenne. Matorral halófilo y gipsófilo. Seven Rivers Hills, Lakewood y Eddy Cos., N.M.

$* *(* * *)$ Eriogonum havardii S. Watson. Hierba perenne. Matorral xerófilo, bosque de juníperos y pastizal. Eddy, Chaves, Otero y Socorro Cos., N.M.; Brewster, Culberson, El Paso, Hudspeth, TransPecos, Presidio y Val Verde Cos., Tex.

*(***) Eriogonum hemipterum (Torr. \& A. Gray) S. Stokes var. griseum I.M. Johnst. Hierba perenne. Bosque de pino-encino. Sierra del Diablo, Chih.; Sierra del Pino, Coah.

*(***) Eriogonum hemipterum (Torr. \& A. Gray) S. Stokes var. hemipterum. Hierba perenne. Bosque de pino-encino. Sierras El Carmen y Santa Rosa, Coah.; Montañas de Chisos, Tex.

* Eriogonum henricksonii Reveal. Hierba perenne. Matorral xerófilo. Sierra Las Delicias, Coah.

** Eriogonum jamesii Benth. var. undulatum (Benth.) S. Stokes ex M.E. Jones. Hierba perenne. Matorral xerófilo y bosque de pinoencino. Cochise Co. y Montañas de Chiricahua, Ariz.; Chaves Co., N.M.; Trans-Pecos, Tex.

* Eriogonum suffruticosum S. Watson. Hierba perenne. Matorral xerófilo. Graham Co., Ariz.; Jeff Davis y Brewster Cos., Tex.

* Eriogonum turneri Reveal. Hierba perenne. Matorral halófilo y gipsófilo. San Roberto y El Refugio, N.L.

* Eriogonum viscanum W.J. Hess \& Reveal. Hierba perenne. Matorral xerófilo. Cedral, S.L.P.; Concepción del Oro, Zac.

Portulacaceae $(350 / 19 / 1)$

** Phemeranthus brevicaulis (S. Watson) Kiger. Hierba perenne. Matorral xerófilo. Sierra Santa Eulalia, Coah.; N.M.; Trans-Pecos, Tex.

Primulaceae (500/8/2)

* Samolus dichondrifolius Channell. Hierba perenne. Matorral halófilo y gipsófilo. Sierra Las Delicias, Coah.
* Samolus ebracteatus Kunth var. coahuilensis Henrickson. Hierba perenne. Matorrales halófilo y gipsófilo. Sierras Las Delicias, de Parras y Cuatro Ciénegas, Coah.

Ranunculaceae (2000/19/2)

** Clematis coahuilensis D.J. Keil. Arbusto. Matorral submontano y bosque de pino-encino. Sierras La Madera, La Gloria, Jimulco, Coah.; Sierra El Rosario, Dgo.; Lampazos, N.L.

*(***) Talictrum henricksonii M.C. Johnst. Hierba perenne. Matorral submontano y bosque de pino-encino. Pico de Teyra, Zac.

Rhamnaceae (850/27/3)

** Condalia warnockii M.C. Johnst. var. warnockii. Arbusto. Matorral xerófilo. Sierras El Fraile y Jimulco, Coah.; cerca de Zimapán, Hgo.; Cedros, Zac.

*(***) Rhamnus standleyana C.B. Wolf. Arbusto. Bosque de pinoencino. Sierras La Madera y La Paila, Coah.

* Ziziphus lloydi M.C. Johnst. Arbusto. Matorral xerófilo. Sierra La Ventura, Coah.; San Roberto, N.L.; Las Charcas y El Huizache, S.L.P.; Cedros, Zac. Rosaceae (3000/44/6)

*(***) Crataegus johnstonii J.B. Phipps. Arbusto. Bosque de coníferas. Sierras El Carmen, Santa Rosa y El Jardín, Coah.

*(***) Crataegus tracyi Ashe ex Eggl. var. coahuilensis J.B. Phipps. Árbol. Bosque de pino-encino. Sierra El Carmen, Coah.

*(***) Prunus cercocarpifolia Villarreal. Arbusto. Matorral submontano. Cerca de Saltillo, Coah.

*(***) Prunus havardii (W. Wight) S.C. Mason. Arbusto. Matorral submontano y bosque de pino-encino. Santo Domingo, Chih.; Brewster y Presidio Cos., Tex.

*(***) Prunus murrayana E.J. Palmer. Arbusto. Bosque de pinoencino. Monte del Elefante, Big Aguja, Brewster, Jeff Davis Cos., y Trans-Pecos, Tex.

*(***) Rosa woodsii Lindl. var. maderensis Henrickson. Arbusto. Bosque de pino-encino. Sierra La Madera, Coah.

Rubiaceae (6000/35/9)

* Chiococca henricksonii M.C. Johnst. Arbusto. Matorral xerófilo. Sierras Las Delicias y La Fragua, Coah.

* Coutaportla pailensis Villarreal. Arbusto. Matorral xerófilo. Sierra La Paila, Coah.

*(***) Galium carmenicola Dempster. Hierba perenne. Bosque de pino-encino. Sierras El Carmen y Santa Rosa, Coah.

*(***) Galium mexicanum Kunth subsp. flexicum Dempster Hierba perenne. Bosque de pino-encino. Sierras El Carmen y Santa Rosa, Coah.; Montañas de Chisos, Tex.

* Hedyotis teretifolia (Terrell.) G.L. Nesom. Arbusto. Matorral xerófilo. Sierras Las Delicias y Las Margaritas, Coah.

*(***) Machaonia pringlei A. Gray. Arbusto. Matorral submontano. Sierra Jimulco, Coah. 
Apéndice: Continuación.

*(***) Randia pringlei (S. Watson) A. Gray. Arbusto. Matorral submontano. Sierras Mojada, Jimulco, de Parras, Almagre y Torreón, Coah.; Sierras Los Alamos y El Rosario, Dgo.

* Stenaria butterwickiae (Terrell) Terrell. Hierba perenne. Matorral xerófilo. S de Sanderson, Tex.

*(***) Stenaria mullerae (Fosberg) Terrell. Arbusto. Matorral submontano. Sierras La Fragua, La Madera y San Marcos, Coah.

Rutaceae (900/13/5)

**(***) Choisya dumosa (Torr.) A. Gray. Arbusto. Matorral submontano y bosque de pino-encino. Sierra Hechiceros, Chih.; Hidalgo y Otero, N.M.; Trans-Pecos, Tex.

*(***) Choisya katherinae C.H. Mull. Arbusto. Matorral submontano. Sierra El Pulpito, Chih.; Sierras La Madera, Jimulco y Mojada, Coah. **(***) Choisya palmeri Standl. Arbusto. Matorral submontano y bosque de pino piñonero. Sierra La Paila, Coah.; Galeana, N.L.; Sierra Catorce, S.L.P.; Sierra San Julián, Zac.

* Thamnosma pailense M.C. Johnst. Subarbusto. Matorral xerófilo. Sierra La Paila, Coah.

*(***) Thamnosma stanfordii I.M. Johnst. Subarbusto. Matorral submontano. Sierras Jimulco, de Parras y Las Delicias, Coah.

Scrophulariaceae $(300 / 12 / 2)$

** Leucophyllum alejandrae G.L. Nesom. Arbusto. Matorral halófilo y gipsófilo. San Roberto y El Salero, Galeana, y Aramberri, N.L.; S de San Ignacio, Tex.

* Leucophyllum coahuilensis Henrickson. Arbusto. Matorral halófilo y gipsófilo. N de San Pedro de las Colonias, Coah.

Simaroubaceae $(120 / 2 / 1)$

* Castela stewartii (C.H. Mull.) Moran \& Felger. Arbusto. Matorral xerófilo. Sierra del Diablo, Chih.; Cuatro Ciénegas, Ramos Arizpe y Saltillo, Coah.; Sierra Catorce, S.L.P.; Trans-Pecos, Tex.; Concepción del Oro, Zac.

Solanaceae (2500/73/14)

* Chamaesaracha geohintonii Averett \& B.L. Turner. Hierba perenne. Matorral halófilo y gipsófilo. Mina, N.L.

* Lycium arochae F. Chiang, T. Wendt \& E.J. Lott. Arbusto. Matorral xerófilo. Sierra Mojada, Coah.

* Lycium berlandieri Dunal var. parviflorum (A. Gray) A. Terracc. Arbusto. Matorral halófilo y gipsófilo. Río Grande, N.M.; Las Charcas, S.L.P.; Trans-Pecos, Tex.

* Lycium californicum Nutt. ex A. Gray var. interior F. Chiang. Arbusto. Matorral xerófilo. Laguna La Leche, Llano del Guaje, entre Lomas El Aparejo y Tanque La India y Puerto de Rocamontes, Coah.; El Cedral, S.L.P.

* Lycium leiospermum I.M. Johnst. Arbusto. Matorral halófilo y gipsófilo. Viesca, Coah.; Galeana, N.L.; Matehuala, S.L.P.; Concepción del Oro, Zac.
* Lycium parishii A. Gray var. modestum (I.M. Johnst.) F. Chiang. Arbusto. Matorral xerófilo. Cuatro Ciénegas, Coah.; San Roberto, N.L.; El Cedral, S.L.P.

* Lycium puberulum A. Gray var. berberioides (Correll) F. Chiang. Arbusto. Matorral xerófilo. Brewster y SE de Presidio Cos., Tex.

* Lycium puberulum A. Gray var. puberulum. Arbusto. Matorral halófilo y gipsófilo. Bolsón de Mapimí, Chih.; Coah.; Dgo.; S de Tex.

* Lycium schaffneri A. Gray ex Hemsl. Arbusto. Matorral xerófilo, halófilo y gipsófilo. Galeana, N.L.; Sierra de Guadalupe, S.L.P.; Saín Alto, Zac.

* Lycium texanum Correll. Arbusto. Matorral xerófilo. Trans-Pecos, Tex.

**(***) Physalis microphysa A. Gray. Hierba perenne. Matorral submontano. Sierra Santa Eulalia, Chih.; Cuatro Ciénegas, Coah.; Aramberri, N.L.; Matehuala, S.L.P

* Solanum davisense Whalen. Hierba anual. Vegetación riparia. Sierra El Carmen, Coah.; Montañas de Davis y Chinati, Tex.

*(***) Solanum fendleri A. Gray var. texense Correll. Hierba perenne. Matorral submontano. Montañas de Davis y Cañon Aguja, Tex.

* Solanum johnstonii Whalen. Hierba perenne. Matorral xerófilo. Sierra Jimulco, Coah.; Sierra El Rosario, Dgo.

*(***) Solanum leptosepalum Correll. Hierba perenne. Matorral submontano y bosque de pino-encino. Sierra Rica, Chih.; Sierras La Madera y La Gloria, Coah.; Montañas de Chinati, Tex.

Verbenaceae (2600/35/5)

* Bouchea linifolia A. Gray ex Torr. Hierba perenne. Matorral xerófilo y submontano y bosque de pino piñonero. Sierras La Gloria, Santa Rosa y Mojada, Coah.; Presidio, Pecos y Val Verde Cos., Tex.

* Bouchea spathulata Torr. var. longiflora Moldenke. Arbusto. Matorral xerófilo y submontano y bosque de pino piñonero. Sierra Almagre, Chih.; Cuatro Ciénegas, Coah.

* Bouchea spathulata Torr. var. spathulata. Arbusto. Matorral xerófilo, submontano y bosque de pino piñonero. Sierras Los Órganos y La Paila, Coah.; Trans-Pecos y Brewster Co., Tex.

* Glandularia alejandrana B.L. Turner. Hierba anual. Matorral halófilo y gipsófilo. Rancho El Aguililla y Valle de Navidad, Galeana, N.L.

* Lippia appendiculata B.L. Rob. \& Greenm. Hierba perenne. Matorral halófilo y gipsófilo. N de Jiménez, Chih.; Laguna La Leche y El Coyote, Coah.; Bolsón de Mapimí, Dgo.; Matehuala, S.L.P.

* Tetraclea subinclusa I.M. Johnst. Hierba perenne. Matorral halófilo y gipsófilo. Cuatro Ciénegas, Coah.

Zygophyllaceae (250/15/3)

* Fagonia scoparia Brandegee. Subarbusto. Matorral halófilo y gipsófilo. Bolsón de Mapimí, Chih.; Sierra Las Delicias y Cuatro Ciénegas, Coah.; Bolsón de Mapimí, Dgo. 
Villarreal-Quintanilla et al.: Plantas endémicas del Desierto Chihuahuense

Apéndice: Continuación.

* Kallstroemia perennans B.L. Turner. Hierba perenne. Matorral xerófilo. Langtry, Val Verde, Presidio y Brewster Cos., Tex.

* Sericodes greggii A. Gray. Arbusto. Matorral xerófilo. Viesca, Sierra de la Paila, Estación Hermanas, Llano El Guaje, Coah.; NE de Dgo.; O y C de N.L.; $\mathrm{N}$ de Zac. 